\title{
The role of DNA methylation in the development and progression of lung adenocarcinoma
}

\author{
Keith M. Kerr ${ }^{\mathrm{a}}$, Janice S. Galler ${ }^{\mathrm{b}}$, Jeffrey A. Hagen ${ }^{\mathrm{c}}$, Peter W. Laird ${ }^{\mathrm{b}, \mathrm{c}}$ and Ite A. Laird-Offringa ${ }^{\mathrm{b}, \mathrm{c}, *}$ \\ ${ }^{a}$ Department of Pathology, Aberdeen Royal Infirmary, Link Building, Foresterhill, Aberdeen, AB25 2ZN, UK \\ ${ }^{\mathrm{b}}$ Department of Biochemistry and Molecular Biology, University of Southern California, Keck School of Medicine, \\ Norris Comprehensive Cancer Center, 1441 Eastlake Ave. Rm NOR6420, Los Angeles, CA 90089-9176, USA \\ ${ }^{\mathrm{c}}$ Department of Surgery, University of Southern California, Keck School of Medicine, Norris Comprehensive \\ Cancer Center, 1441 Eastlake Ave. Rm NOR6420, Los Angeles, CA 90089-9176, USA
}

\begin{abstract}
Lung cancer, caused by smoking in $\sim 87 \%$ of cases, is the leading cause of cancer death in the United States and Western Europe. Adenocarcinoma is now the most common type of lung cancer in men and women in the United States, and the histological subtype most frequently seen in never-smokers and former smokers. The increasing frequency of adenocarcinoma, which occurs more peripherally in the lung, is thought to be at least partially related to modifications in cigarette manufacturing that have led to a change in the depth of smoke inhalation. The rising incidence of lung adenocarcinoma and its lethal nature underline the importance of understanding the development and progression of this disease. Alterations in DNA methylation are recognized as key epigenetic changes in cancer, contributing to chromosomal instability through global hypomethylation, and aberrant gene expression through alterations in the methylation levels at promoter $\mathrm{CpG}$ islands. The identification of sequential changes in DNA methylation during progression and metastasis of lung adenocarcinoma, and the elucidation of their interplay with genetic changes, will broaden our molecular understanding of this disease, providing insights that may be applicable to the development of targeted drugs, as well as powerful markers for early detection and patient classification.
\end{abstract}

Keywords: AAH, adenocarcinoma, BAC, CpG island, DNA methylation, hypermethylation, hypomethylation

\section{Introduction}

Lung cancer is the leading cause of cancer death in the United States and Western Europe for both men and women, taking over 163,000 American lives in 2005 [1, 2]. Approximately $87 \%$ of lung cancer cases are caused by exposure to tobacco products [3]. Unfortunately, the marked decrease in smoking in the United States, observed for men in the 1970s and 1980s, appears to be leveling off [4], and in 2002, approximately $25 \%$ of men and over $20 \%$ of women in the United States

* Corresponding author: Ite A. Laird-Offringa, Ph.D., USC/Norris Cancer Center, 1441 Eastlake Ave. Rm NOR6420, Los Angeles, CA 90089-9176, USA. Tel.: +1 323865 0655; Fax: +1 323865 0158; E-mail: ilaird@usc.edu. smoked [4]. A roughly similar situation prevails in many West European countries. In addition, a large number of previous longtime smokers remain at high risk for lung cancer development for years after smoking cessation; a recent study of a prospective cohort of Iowa women showed that for adenocarcinoma, former smokers had an elevated risk for up to 30 years after quitting smoking [5]. Lung cancer is clinically subdivided into small cell lung cancer (SCLC; 15-20\% of lung cancers), the most aggressive form of lung cancer, and non-small cell lung cancer (NSCLC), consisting of adenocarcinoma, squamous cell carcinoma, large cell carcinoma, and miscellaneous other types such as carcinoids, pleomorphic and mixed carcinomas and a range of neuroendocrine cancers [6]. In the United States, adenocarcinoma has now surpassed squamous 
cell cancer as the most common histological subtype of lung cancer, and continues to increase worldwide, particularly in women [7-9]. Adenocarcinoma generally arises more peripherally in the lung. Its increased incidence is thought to be related at least in part to changes in the structure and composition of cigarettes (lower tar, lower nicotine, leading to deeper inhalation) $[10$, 11]. Adenocarcinoma is also the most common type of lung cancer in previous and never-smokers, and among young patients with adenocarcinoma, the percentage of women and non-smokers is unusually high [12]. Recently, certain human papilloma virus subtypes have been implicated in adenocarcinoma in non-smoking women in Asian countries (reviewed in [13]). These observations point to the importance of gaining a better understanding in the etiology of lung adenocarcinoma, and in the molecular changes underlying this disease.

The study of genetic mutations/deletions has provided important mechanistic insight into tumorigenesis in many different organs. However, it has recently become clear that epigenetic alterations also play an important role in cancer development. Epigenetic changes are heritable through cell division, and result in altered gene activity without any accompanying changes in the DNA sequence $[14,15]$. The most easily quantifiable and best characterized epigenetic alteration in cancer is a change in the pattern of DNA methylation. This review will be limited to the discussion of DNA methylation-based epigenetic alterations.

In mammals, DNA methylation predominantly consists of the addition of a methyl group to the 5 position of cytosine, primarily at $\mathrm{CpG}$ dinucleotides. This is a normal and essential enzymatic modification that is required for proper development of the organism (recently reviewed in [16]). DNA methylation is required for chromosomal stability, and is a powerful mechanism for maintaining the suppression of gene activity in vertebrates, for example in X-chromosome inactivation [14,17-20]. In cancer, the pattern of DNA methylation normally seen in healthy cells is altered; there is a global loss of methylation, associated with chromosomal instability, and local changes in methylation in clusters of $\mathrm{CpGs}$, or $\mathrm{CpG}$ islands [16,20,21]. CpG islands are G:C- and CpG-rich areas of about $1 \mathrm{~kb}$, often found near the gene promoter in the case of widely expressed genes [22-24]. During carcinogenesis, certain genes can become activated through loss of $\mathrm{CpG}$ island methylation, sometimes associated with loss of maternal or paternal imprinting [25]. However, a much more commonly observed alteration at $\mathrm{CpG}$ islands is hypermethylation, which is seen as a key mecha- nism for the inactivation of genes that, in a variety of ways, normally contribute to negative regulation of cell growth. The relationship between promoter methylation of cytosine residues and the transcriptional silencing of genes has been widely documented $[18,19,26]$.

De novo methylation of 5' $\mathrm{CpG}$ islands is occasionally seen in normal somatic tissues, particularly in the case of certain genes that show a gradual increase in methylation during aging [27]. However, this is much more common in cancer: hypermethylation of $\mathrm{CpG}$ islands has been observed in virtually every type of human cancer that has been investigated [20,28, 29 ], including lung cancer (recently reviewed in [30$32]$ ). Because $\sim 40 \%$ of human genes carry promoter $\mathrm{CpG}$ islands [33], $\mathrm{CpG}$ island hypo- and hypermethylation provides an enormous potential for epigenetic alterations in cancer, giving rise to phenotypic changes which, combined with genetic alterations, underlie cancer development and progression [25,28,29, $34,35]$. Studies of DNA methylation in lung cancer to date strongly suggest that the analysis of DNA methylation profiles will be of great utility both for understanding the molecular basis of lung cancer development [36-39], and for developing tools for accurate and early lung cancer diagnosis and prognostication $[21,30$, 31]. In addition, the reversibility of DNA methylation suggests that clinical strategies might be developed to reactivate genes silenced by methylation [40].

Much current work still focuses on the important and gargantuan task of cataloging cancer-specific DNA methylation alterations in lung cancer, a task that is far from complete. However, recently some of the focus has shifted to the mapping of sequential DNA methylation changes during cancer initiation and progression, and the clarification of how epigenetic and genetic changes collude to promote cancer development. In colon adenocarcinoma, studies of cancer at different stages has allowed elegant sequential models of cancer progression to be developed [41,42]. In lung cancer such work is more challenging, as samples of early lesions are much more difficult to obtain. However, work from animal models combined with studies of human tissues, blood and sputum samples, have begun to yield insights into early and late DNA methylation changes [31]. Here we will discuss what is known about the timing of DNA methylation alterations in lung adenocarcinoma, and how these changes might interface with known genetic alterations. Although there are numerous reports of methylation in lung cancer in general, many lack information about histology, the relationship between methylation and tumor stage, or whether 
methylation is present in non-tumor tissue. Since reports lacking any such information do not shed light on progressive methylation in developing lung adenocarcinoma, they will not be cited here. For a broader overview of DNA methylation in lung cancer the reader is referred to previously published reviews [30-32].

\section{Development and progression of lung adenocarcinoma}

In order to begin mapping out the chronology of epigenetic changes in the development and progression of lung adenocarcinoma, it is important to obtain an overview of the different stages leading to advanced lung adenocarcinoma. This knowledge, summarized in Fig. 1, will form the framework into which data about epigenetic alterations will be incorporated. The first step (Fig. 1, step 1) represents the acquisition of genetic or epigenetic changes that affect large sections of the lung. Environmental exposures are assumed to be to blame for these large regional (epi)genetic changes, which are referred to as field effects or defects [4345] and which also have been called field "cancerization" [46]. Longtime smoking, which is considered to be the cause of lung cancer in $\sim 85 \%$ of cases, and other exposures such as asbestos and radiation, likely play a role in generating (epi)genetically altered fields [47]. More recently, certain strains of human papilloma virus have been implicated in lung cancer, in particular in non-smoking Asian women (reviewed in [13]), and these could likewise lead to (epi)genetic alterations. The influence of the environment on the epigenome is well illustrated by the demonstration that epigenetic differences arise in monozygotic twins during their lifetime [48]. Indeed, analysis of DNA methylation of histologically normal bronchial margins of lung cancer patients shows frequent hypermethylation similar to that seen in the tumors [43]. This is reminiscent of field defects showing DNA hypermethylation in colon cancer [49]. The fact that field defects are found in healthy-looking microdissected lung [50] argues against an inflammatory explanation, and its association with smoking reinforces the idea that the environment plays a strong role (see below).

Field defects would predispose cell populations in the lung to the development of microscopically visible precancerous lesions. This is precisely what is seen in $\sim 20 \%$ of lung cancer patients: they carry atypical adenomatous hyperplasia (AAH, Fig. 1, step 2) in their adjacent non-tumor lung tissue, sometimes as a multitude of individual tiny lesions [51]. AAH consists of runs of cuboidal cells lining slightly thickened alveolar walls (see Fig. 1 [52]). The suggestion that AAH is a precursor of lung adenocarcinoma is based on several observations. First, AAH occurs predominantly in lung adenocarcinoma patients; 72-81\% of AAH lesions are found in patients with a primary adenocarcinoma [51,53,54]. Second, activating KRAS point mutations, which are found in $\sim 30 \%$ of lung adenocarcinomas [55], have been found with similar frequency in AAH in at least one study [56]. Third, analysis of X-chromosome inactivation in individual AAH lesions has shown that they are monoclonal, while similar sized reactive metaplastic lesions are not, indicating that AAH represents outgrowth of a single altered cell [57]. In addition, AAH lesions and contiguous bronchioalveolar carcinoma were also shown to be monoclonal [57]. It has been proposed that cancer stem cells could play a role in the development of early precancerous lesions in defective fields [25]. The recent identification of potential lung cancer stem cells that appear to be precursors for lung adenocarcinoma in a mouse model system lends credence to this idea [58,59].

AAH lesions vary in their cellularity and atypia, ranging from relatively low grade lesions to those with higher grade changes. The latter is presumably a progression of the former, and is very similar to localized non-mucinous bronchioalveolar carcinoma [51] (BAC, Fig. 1, step 3). According to the new WHO classification, BAC is defined as a non-invasive lesion [60]. Pure localized BACs are rare, as any invasive component must be completely excluded [61]. BAC is considered the likely intermediary stage between AAH and invasive adenocarcinoma [51,53,57,61,62].

Once invasion has developed within BAC, the lesion is considered adenocarcinoma (Fig. 1, step 4), and its progression is reflected in the clinically or pathologically assigned stage (Fig. 1, step 5). Staging is of key importance for the clinical management of patients, and to provide prognostic indicators [63]. Staging can be clinical (based on physical examination and imaging) or surgical-pathologic (based on surgery with accompanying lymph node dissection and pathologic description of the extent of tumor spread). The assigned stage is based on the TNM system: $\mathrm{T}$ is determined by the size of the tumor and/or its location (T1-3). $\mathrm{N}$ is determined by the involvement (or not) of lymph nodes (N0, no positive nodes, N1, involvement of peribronchial and/or ipsilateral hilar region nodes; $\mathrm{N} 2$, involvement of ipsilateral mediastinal or subcarinal nodes; N3, involvement of contralateral mediasti- 


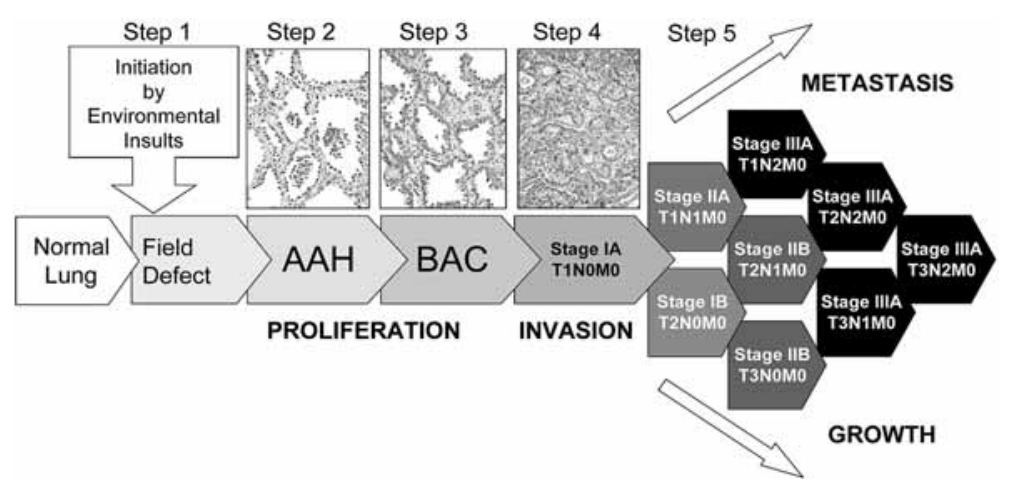

Fig. 1. Development and progression of lung adenocarcinoma. Step 1: Environmental exposures, such as tobacco smoke, radiation, asbestos, viral infection, etc. lead to histologically invisible changes that result in molecularly altered fields of cells (a process often referred to as "field cancerization"). Presumably, the response to environmental insults is modulated by the subject's genetic background. Environmental exposures can continue throughout all following steps, and are thought to stimulate progression. Step 2: Within these altered fields, additional (epi)genetic changes are acquired, leading to phenotypic changes in affected cells and the formation of small histologically visible lesions (AAH). Step 3: AAH lesions progress, acquiring further (epi)genetic changes, retaining alveolar structure, developing more cytological atypia but not yet becoming invasive, resulting in bronchioalveolar carcinoma. Step 4: (Epi)genetic changes continue, allowing cells within BAC to become invasive. Step 5: Further molecular alterations allow growth in size of adenocarcinoma and metastasis to nodes and eventually other organs.

nal or hilar nodes, or ipsilateral/contralateral scalene or supraclavicular nodes) [64]. M status is determined by nodal spread beyond N3 node stations and/or to distant organs (M0 none, M1 metastases).

The importance of studying the molecular changes in these different stages of lung adenocarcinoma is supported by two observations. The first is that lung cancer patient survival differs for the distinct stages [63]. Survival of each pathologic stage is better than its corresponding clinical stage, because clinically staged cases showing previously undetected lymph node metastases (N0) are moved up in stage upon discovery of involved nodes ("stage migration") [64]. Nevertheless, statistically significant differences in 5-year survival are seen between all early clinical stages except between IIA (T1N1M0) and IIB (T2N1M0), and all early pathologic stages [63]. In addition, statistically significant differences are seen between survival of all different $\mathrm{N}$ designations (clinical or pathologic) [64]. For example, for clinical N0 vs. N1, the 5-year survival is $\sim 40 \mathrm{vs}$. $\sim 20 \%$, whereas for pathologic N0 vs. N1 it is $\sim 60$ vs. $\sim 40 \%$. A second reason why knowledge of molecular changes in the various stages is important, is that even in pathologic stage N0 disease, only $\sim 60 \%$ of patients will survive $\geqslant 5$ years. Pathologic N0 patients, cumulatively referred to as stage I, fall into two sub-stages: IA, which is T1N0M0, and IB, which is T2N0M0. Stages IA and IB show statistically significant differences in 5 -yr survival (67 and 57\% respectively), but the basis for this difference remains unknown. It is assumed that molecular alterations, in other words, genetic and/or epigenetic changes, are responsible for these survival disparities. Patients who have successful resection of pathologic Stage I disease yet later succumb to the same disease are presumed to have had undetectable micrometastases at the time of surgery.

\section{The interplay of genetic and epigenetic alterations}

Genetic and epigenetic events both contribute to the development and progression of lung adenocarcinoma, and these changes have the potential to affect each other [25,65]. Epigenetic silencing of DNA repair genes such as MGMT or MLH1 might predispose cells to the acquisition of further genetic hits [49,66,67], while mutations in genes involved directly or indirectly in de novo or maintenance methylation could affect DNA methylation levels [68-72]. Dissecting the respective epigenetic and genetic contributions, and determining the timing with which (epi)genetic events occur during carcinogenesis, is one of the most exciting challenges in the field.

Our ability to construct timelines of (epi)genetic hits is hampered by two major obstacles. The first is that knowledge about the timing of these hits remains limited, because it is often unclear when these changes first appear. Indeed, the same alteration can occur at different times in different patients. We shall consider them "early" if they occur with a measurable frequency in precancerous tissue, even if they become more frequent at later stages. The second is that most (epi)genetic alterations will not be fully penetrant; in other words, 
only a fraction of lesions or tumors will carry a particular molecular change. This is because pathways are the targets of (epi)genetic hits rather than individual genes [73]. The molecular pathways for cell survival, growth in response to signaling, the ability to proliferate in an anchorage independent fashion, etc. are complex and each involve a large number of factors. Distinct genes in a single pathway may be affected in different patients, giving rise to the same phenotypic result. Adding further complexity, (epi)genetic hits might be acquired at later stages in already disrupted pathways, perhaps even in the same gene, leading to a more profound deregulation. Thus, it is crucially important to see individual (epi)genetic events in a larger context, each as an alteration in a particular subsection of the cellular circuitry. We will take this into consideration as we begin to piece together the (epi)genetic puzzle of lung adenocarcinoma development and progression. Although many pieces of this puzzle are still missing, it will nevertheless provide a framework within which newly identified hits can be placed.

\section{Early (epi)genetic changes: Histologically normal lung}

As outlined in Fig. 1, the earliest pathways altered in cancer development would allow proliferation of certain cell groups and would provide fertile ground for subsequently arising lesions. These pathways would likely be related to growth control, differentiation and/or apoptosis. Because the earliest changes may not be visible at the histological level, they may be very difficult to characterize. One way to do so would be to ask: What kind of (epi)genetic changes are observed in the lung from areas adjacent to lung cancers, and how do these areas compare to regions further from the tumor? An autopsy study on the lungs of a cancerfree smoker showed an identical p53 mutation in 7 out of 10 widely separated sampled sites, but no such mutation in blood or non-pulmonary organs [74]. While this is an isolated case, and p53 mutations do not appear to be very common in lung adenocarcinoma, it suggests that somatic mutations can occur early and might spread widely throughout the lungs, perhaps through the migration of cancer stem cells.

Distinct regions of loss of heterozygosity $(\mathrm{LOH})$ of chromosome $3 p$ have been found in normal lung from many lung cancer patients $[75,76]$, and microsatellite analysis has indicated multiple potentially clonal but relatively small patches carrying such molecular abnor- malities [77]. LOH of chromosomes $2 q$ and $12 p$ is also found in over $10 \%$ of normal epithelial samples from lung cancer patients, and like $3 \mathrm{p} \mathrm{LOH}$, these losses are significantly associated with smoking $[78,79]$. LOH of chromosomes $9 \mathrm{p}$ and $8 \mathrm{p}$ seems less frequent but also occurs early, suggesting it might follow deletions on other chromosomes [80]. Thus, LOH at certain chromosomal regions appears to be a very early event during the development of precancerous fields. Which genes are targeted is still unclear, but observed hypermethylation of loci in the areas of LOH might provide clues (see below).

Interestingly, an analysis by Wistuba et al. of the specific parental allele lost in multiple preneoplastic lesions and squamous cell lung carcinomas from the same patients indicated that the $3 \mathrm{p}$ allele loss was nonrandom [75]. Could such allele-specific events perhaps be linked to DNA methylation changes arising from loss of parental imprinting (LOI)? Global loss of imprinting in a mouse model leads to widespread tumorigenesis in various organs [81]. The imprinted locus H19 has been shown to be monoallelically upregulated (without LOI) in histologically normal lung from smokers [82], and LOI-mediated overexpression of $\mathrm{H} 19$ has been found to be frequent in lung cancer [83]. LOI of the MEST and IGF2 genes is also frequent in lung adenocarcinoma [84,85]. Thus, LOI occurs in lung cancer, and could perhaps be related to allele-specific chromosomal losses. However, at this time there is little evidence for fields of LOI in histologically normal lung [84]. Pinpointing the timing of LOI events will require further investigation and may show that LOI occurs at different times for different loci [84].

It has been widely documented that global hypomethylation, i.e. the loss of methylation seen at sporadic (non-CpG island) $\mathrm{CpGs}$ is seen in many types of cancer. This has been shown to contribute to chromosomal instability, and thus could be a factor in early $\mathrm{LOH}$ events. Studies of global hypomethylation in human squamous cell lung cancer showed hypomethylation of the cancers compared to uninvolved bronchial mucosa and hyperplastic epithelium, suggesting that global hypomethylation is not an early event [86]. Mouse experiments with DNA methyltransferase hypomorphs have demonstrated that reducing global methylation severely limits the development colon adenocarcinoma, while promoting lymphomas, cancers that appear to rely heavily on chromosomal rearrangements $[87,88]$. Based on the parallels between colon adenocarcinoma and lung adenocarcinoma, these animal experiments would suggest that during early stages of cancer de- 
velopment, hypermethylation is much more important than hypomethylation. This would imply that global demethylation does not underlie early instances of LOH.

What then causes early LOH? Perhaps these local chromosomal losses are repair deficiencies associated with carcinogen-induced damage and possible loss of repair gene function. Genes involved in repair might be mutated or silenced, for example by $\mathrm{CpG}$ island hypermethylation. Analysis of adjacent non-tumor lung from lung cancer patients, non-tumor lung from non-cancer patients, and bodily fluids from clinically free cancer patients (sputum, bronchioaveolar lavage, blood) has provided ample evidence for hypermethylation as a very early event in lung cancer development. Table 1 , column 3 indicates whether methylation of certain loci has been found in histologically normal lung.

The presence of hypermethylation in tumor margins suggests that altered fields of cells exist in the lung [43]. Substantial evidence supports a role for environmental exposures in promoting such changes. An excellent study of lung biopsies from smokers and nonsmokers showed CDKN2A methylation in $18 \%$ of noncancerous biopsies from smokers, but no methylation in biopsies from never-smokers [89], suggesting that epigenetic changes arise in response to environmental insults. In addition, hypermethylation of CDKN2A in lung lobes without cancer was concordant with the primary tumor in almost all cases, suggesting frequent occurrence of methylation of this locus in bronchial epithelium of smokers [89]. Hypermethylation of RARB, CDKN2A, DAPK, RASSF1A and MGMT was observed in the serum of non-cancer cases, and was more frequent in $\geqslant 40$ pack-year smokers [90]. Hypermethylation of CDKN2A and MGMT has also been observed in sputum from cancer-free smokers [91-94], and hypermethylation of CDKN2A, RASSF1A, MGMT and $\mathrm{APC}$ in non-small cell lung cancer are more frequent with increasing years of smoking $[38,39,95,96]$. The role of smoking in causing hypermethylation is further supported by the fact that the number of methylated loci (the "methylation index"), is progressively elevated in former smokers and current smokers [39].

Methylation-based silencing could complement $\mathrm{LOH}$, for example of genes on chromosome $3 \mathrm{p}$. Several 3p loci, such as FHIT, RARB, RASSF1, SEMA3B, and TGFBR2 can be methylated to some extent in histologically normal lung (Table 1). SEMA3B, which lies at 3p21.3 and encodes a putative tumor suppressor protein that competes with vascular endothelial growth factor (VEGF) for binding to two neuropilin receptors [97], was shown to be methylated in $\sim 11 \%$ of adjacent non-cancerous lung from lung cancer patients, and $50 \%$ of lung adenocarcinomas [98]. Like SEMA3B, many loci that show early methylation exhibit increasingly frequent methylation in BAC and adenocarcinoma (Table 1), suggesting that hypermethylation is progressive during lung adenocarcinoma development. Studies with lung cancer-prone mice demonstrated that reduced expression of the DNA methyltransferase DNMT1 resulted in a 50\% reduction in tobacco carcinogen-induced pulmonary lesions [99]. The effect was even more pronounced when the mice were simultaneously treated with histone deactelylase inhibitors, emphasizing the importance of epigenetic silencing in lung adenocarcinoma development. Aside from tobacco smoke, components of diesel exhaust have also been shown to increase CDKN2A methylation in rats [100]. Together, these observations support a role for environmental insults such (as smoking) in DNA methylation changes that could be initiated at a time when lung tissue appears histologically normal.

It has been proposed that tobacco smoke could promote epithelial-mesenchymal transition of cells in lung cancer, through its effect on pathways such as WNT, thereby disrupting intracellular communications, promoting cell motility and causing changes in gene expression [101]. Indeed, the WNT pathway has been implicated in self-renewal of stem cells [102]. APC is a well known negative regulator of WNT, that is mutated in familial colon cancer [103]. Because in lung cancer few mutations have been found in APC, pathways for WNT activation distinct from the canonical pathways have been proposed [102]. However, hypermethylation of APC is commonly observed in lung cancer as well as in histologically normal lung from older subjects, and thus epigenetic silencing of APC could represent a mechanism for WNT pathway activation in the lung $[38,50]$.

A possible confounding factor in the analysis of methylation in non-tumor lung is age-related hypermethylation [27,104]. Analysis of autopsy lung from non-lung cancer patients showed an elevated frequency of methylation in subjects older than 44 years of age, compared to subjects younger than 32 years old [105]. In the younger subjects, only APC was methylated (in about $30 \%$ of cases), whereas in the older group, $17 \%$ of subjects showed DAPK and CDH1 methylation and $5-6 \%$ of cases exhibited methylation of CDKN2A, RASSF1 and/or RUNX3. These observations reinforce the notion that aging alone can lead to hypermethylation, a consideration that should be kept in mind as re- 
Table 1

Hypermethylation of loci in histologically normal lung tissue (from non-lung cancer patients or from tissue adjacent to lung cancer) and in lung adenocarcinoma

\begin{tabular}{|c|c|c|c|c|}
\hline $\begin{array}{l}\text { Locus } \\
\text { (HUGO Name) }\end{array}$ & $\begin{array}{l}\text { Locus description [chromo- } \\
\text { somal location] }\end{array}$ & $\begin{array}{l}\text { Methylated in } \\
\text { non-tumor lung }\end{array}$ & Methylated in adenocarcinoma & References \\
\hline ACIN1 & $\begin{array}{l}\text { apoptotic chromatin condensation in- } \\
\text { ducer } \\
{[14 \mathrm{q} 11.2]}\end{array}$ & ++ & $\begin{array}{l}\text { More frequently methylated in } \\
\text { tumors. }\end{array}$ & [148] \\
\hline ADAMTS8 & $\begin{array}{l}\text { ADAM metallopeptidase with throm- } \\
\text { bospondin type } 1 \text { motif, } 8 \\
\text { [11q25] }\end{array}$ & + & $\begin{array}{l}\text { More frequently methylated in } \\
\text { tumors. }\end{array}$ & [191] \\
\hline APC & $\begin{array}{l}\text { adenomatosis polyposis coli } \\
\text { [5q21-q22] }\end{array}$ & +++ & $\begin{array}{l}\text { More frequently methylated in } \\
\text { tumors. } \\
\text { More frequently methylated in } \\
\text { smokers. } \\
\text { Associated with poor survival. }\end{array}$ & $\begin{array}{l}{[39,105,192]} \\
{[38,50,184,193-195]}\end{array}$ \\
\hline CALCA & $\begin{array}{l}\text { calcitonin/calcitonin-related polypep- } \\
\text { tide, alpha } \\
{[11 \mathrm{p} 15.4]}\end{array}$ & +++ & $\begin{array}{l}\text { More frequently methylated in } \\
\text { tumors. }\end{array}$ & {$[50]$} \\
\hline CCND2 & $\begin{array}{l}\text { cyclin D2 } \\
{[12 \mathrm{p} 13]}\end{array}$ & - & $\begin{array}{l}40 \% \text { methylated in tumors } \\
\text { (NSCLC). }\end{array}$ & [196] \\
\hline $\mathrm{CDH} 1$ & $\begin{array}{l}\text { cadherin } 1 \text {, type } 1 \text {, E-cadherin (ep- } \\
\text { ithelial) } \\
{[16 \mathrm{q} 22.1]}\end{array}$ & ++ & $\begin{array}{l}\text { More frequently methylated in tu- } \\
\text { mors. } \\
\text { Associated with poor prognosis. }\end{array}$ & {$[50,105,195,197]$} \\
\hline $\mathrm{CDH} 13$ & $\begin{array}{l}\text { cadherin 13, H-cadherin (heart) } \\
\text { [16q24.2] }\end{array}$ & + & $\begin{array}{l}\text { More frequently methylated in } \\
\text { tumors. } \\
\text { No correlation with smoking. } \\
\text { Associated with late stage. }\end{array}$ & {$[39,198-200]$} \\
\hline CDKN1C & $\begin{array}{l}\text { cyclin-dependent kinase inhibitor } 1 \mathrm{C} \\
\text { (p57, Kip2)[11p15.5] }\end{array}$ & - & $\begin{array}{l}\text { Methylated in } 32 \% \text { of tumors } \\
\text { (NSCLC). }\end{array}$ & {$[201]$} \\
\hline CDKN2A & $\begin{array}{l}\text { cyclin-dependent kinase inhibitor } \\
\text { 2A (melanoma, p16, inhibits CDK4) } \\
\text { [9p21] }\end{array}$ & $+/++$ & $\begin{array}{l}\text { More frequently methylated in } \\
\text { tumors. } \\
\text { Methylation correlated with smok- } \\
\text { ing and poor survival. } \\
\text { Increased frequency of methyla- } \\
\text { tion in metastatic lesions. }\end{array}$ & $\begin{array}{l}{[38,39,50,90,93} \\
105,109,115,144, \\
198,200,202-206]\end{array}$ \\
\hline CHFR & $\begin{array}{l}\text { checkpoint with forkhead and ring fin- } \\
\text { ger domains } \\
{[12 q 24.33]}\end{array}$ & - & $\begin{array}{l}10 \% \text { methylated in tumors } \\
\text { (NSCLC). }\end{array}$ & [207] \\
\hline DAB2 & $\begin{array}{l}\text { disabled homolog } 2 \text {, mitogen- } \\
\text { responsive phosphoprotein } \\
\text { (Drosophila) } \\
\text { [5p13] }\end{array}$ & - & $30 \%$ methylated in tumors. & [208] \\
\hline DAPK & $\begin{array}{l}\text { death-associated protein kinase } 1 \\
9 \mathrm{q} 34.1\end{array}$ & ++ & $\begin{array}{l}\text { More frequently methylated } \\
\text { in tumors. } \\
\text { No correlation with smoking. } \\
\text { Associated with poor survival, pos- } \\
\text { itive nodes and late stage. }\end{array}$ & {$[90,105,209-212]$} \\
\hline EPB41L3 & $\begin{array}{l}\text { erythrocyte membrane protein band } \\
4.1-\text { like } 3 \\
{[18 \mathrm{p} 11.32]}\end{array}$ & ND & $\begin{array}{l}\text { Methylation frequency increases } \\
\text { with stage. }\end{array}$ & [213] \\
\hline ESR1 & $\begin{array}{l}\text { estrogen receptor } 1 \\
{[6 \mathrm{q} 24-\mathrm{q} 27]}\end{array}$ & $-/+$ & $\begin{array}{l}\text { Frequently methylated in } \\
\text { (non)smoking men, in women, } \\
\text { predominantly methylated in non- } \\
\text { smokers }\end{array}$ & {$[50,214,215]$} \\
\hline
\end{tabular}




\begin{tabular}{|c|c|c|c|c|}
\hline $\begin{array}{l}\text { Locus } \\
\text { (HUGO Name) }\end{array}$ & $\begin{array}{l}\text { Locus description [chromo- } \\
\text { somal location] }\end{array}$ & $\begin{array}{l}\text { Methylated in } \\
\text { non-tumor lung }\end{array}$ & Methylated in adenocarcinoma & References \\
\hline ESR2 & $\begin{array}{l}\text { estrogen receptor } 2 \text { (ER beta) } \\
{[14 \mathrm{q} 21-\mathrm{q} 22]}\end{array}$ & + & $\begin{array}{l}\text { More frequently methylated in } \\
\text { tumors. }\end{array}$ & {$[50]$} \\
\hline FBN2 & $\begin{array}{l}\text { fibrillin } 2 \text { (congenital contractural } \\
\text { arachnodactyly) } \\
{[5 \mathrm{q} 23-\mathrm{q} 31]}\end{array}$ & + & $\begin{array}{l}\text { More frequently methylated in tu- } \\
\text { mors. } \\
\text { Associated with large tumors and } \\
\text { nodal metastasis. }\end{array}$ & {$[216]$} \\
\hline FHIT & $\begin{array}{l}\text { fragile histidine triad gene } \\
\text { [3p14.2] }\end{array}$ & + & $\begin{array}{l}\text { More frequently methylated in tu- } \\
\text { mors. Methylation correlated with } \\
\text { poor survival by some and in- } \\
\text { vasion/lymph node metastasis by } \\
\text { others. }\end{array}$ & $\begin{array}{l}{[110,197,200,} \\
217-221]\end{array}$ \\
\hline GATA 4,5 & $\begin{array}{l}\text { GATA binding protein } 4,5 \\
{[8 \mathrm{p} 23.1-\mathrm{p} 22,20]}\end{array}$ & $\begin{array}{l}- \text {, but present } \\
\text { in } 50 \% \text { of BAC }\end{array}$ & $\begin{array}{l}\text { More frequently methylated in } \\
\text { tumors. }\end{array}$ & {$[222]$} \\
\hline GJA1 & $\begin{array}{l}\text { gap junction protein, alpha } 1,43 \mathrm{kDa} \\
\text { (connexin } 43 \text { ) } \\
{[6 \mathrm{q} 22-\mathrm{q} 23]}\end{array}$ & ++ & $\begin{array}{l}\text { More frequently methylated in } \\
\text { tumors. }\end{array}$ & {$[223]$} \\
\hline GSTP1 & $\begin{array}{l}\text { glutathione S-transferase pi } \\
\text { [11q13-qter] }\end{array}$ & $-/+$ & $\begin{array}{l}\text { Not a very frequently methylated lo- } \\
\text { cus in tumors. }\end{array}$ & {$[39,50,105]$} \\
\hline $\mathrm{HIC} 1$ & $\begin{array}{l}\text { hypermethylated in cancer } 1 \\
{[17 \mathrm{p} 13.3]}\end{array}$ & ++ & $\begin{array}{l}\text { Methylation frequency increases } \\
\text { with decreasing differentiation. }\end{array}$ & [224] \\
\hline HTR1B & $\begin{array}{l}\text { 5-hydroxy-tryptamine (serotonin) re- } \\
\text { ceptor 1B } \\
{[6 \mathrm{q} 13]}\end{array}$ & ND & Methylated in 6 out of 8 tumors. & [225] \\
\hline HOX genes & $\begin{array}{l}\text { homeobox A, D cluster } \\
\text { [7p15-p14, 2q31-q37] }\end{array}$ & $+/+++$ & $\begin{array}{l}\text { Depending on which HOX gene, } \\
25-100 \% \text { methylated in tumors. }\end{array}$ & {$[109,226]$} \\
\hline IGSF4 & $\begin{array}{l}\text { immunoglobulin superfamily, member } \\
4 \\
\text { [11q23.2] }\end{array}$ & + & $\begin{array}{l}\text { More frequently methylated in } \\
\text { tumors. }\end{array}$ & {$[227]$} \\
\hline LAMA3,B3 & $\begin{array}{l}\text { laminin alpha } 3 \text {, beta } 3 \\
{[18 \mathrm{q} 11.2,1 \mathrm{q} 32]}\end{array}$ & ++ & $\begin{array}{l}\text { More frequently methylated in } \\
\text { tumors. }\end{array}$ & {$[228]$} \\
\hline MGMT & $\begin{array}{l}\text { O-6-methylguanine- } \\
\text { DNA methyltransferase } \\
{[10 \mathrm{q} 26]}\end{array}$ & $+1++$ & $\begin{array}{l}\text { More frequently methylated in tu- } \\
\text { mors. One report of association } \\
\text { with non-smoking status. More } \\
\text { common in larger tumors. }\end{array}$ & $\begin{array}{l}{[39,50,90,93,146,} \\
158]\end{array}$ \\
\hline MLH1 & $\begin{array}{l}\text { mutL homolog } 1 \text {, colon cancer, non- } \\
\text { polyposis type } 2 \text { (E. coli) } \\
{[3 \mathrm{p} 22.3]}\end{array}$ & - & $\begin{array}{l}38 \% \text { methylated in tumors. Methy- } \\
\text { lation correlated with late stage and } \\
\text { poor survival. }\end{array}$ & {$[67,105]$} \\
\hline MTHFR & $\begin{array}{l}\text { 5,10-methylenetetrahydrofolate reduc- } \\
\text { tase (NADPH) } \\
{[1 \mathrm{p} 36.3]}\end{array}$ & +++ & $\begin{array}{l}\text { More frequently methylated in } \\
\text { tumors. }\end{array}$ & {$[50]$} \\
\hline MYO18B & $\begin{array}{l}\text { myosin XVIIIB } \\
{[22 q 11.2-12.1]}\end{array}$ & + & $\begin{array}{l}\text { More frequently methylated in tu- } \\
\text { mors. (NSCLC) }\end{array}$ & [229] \\
\hline MYOD1 & $\begin{array}{l}\text { myogenic differentiation } 1 \\
{[11 \mathrm{p} 15]}\end{array}$ & ++ & $\begin{array}{l}\text { More frequently methylated in } \\
\text { tumors. }\end{array}$ & {$[50]$} \\
\hline PAX5 & $\begin{array}{l}\text { paired box gene } 5 \text { (B-cell lineage spe- } \\
\text { cific activator) } \\
{[9 \mathrm{p} 13]}\end{array}$ & +++ & $\begin{array}{l}50-60 \% \text { methylated in adenocarci- } \\
\text { noma; frequency similar to adjcent } \\
\text { non-tumor lung. }\end{array}$ & [230] \\
\hline PGR & $\begin{array}{l}\text { progesterone receptor } \\
\text { [11q22-q23] }\end{array}$ & ++ & $\begin{array}{l}\text { More frequently methylated in } \\
\text { tumors. }\end{array}$ & {$[50]$} \\
\hline
\end{tabular}


Table 1, continued

$\begin{array}{ll}\begin{array}{l}\text { Locus } \\ \text { (HUGO Name) }\end{array} & \begin{array}{l}\text { Locus description [chromo- } \\ \text { somal location] } \\ \text { PRKCDBP }\end{array} \\ \begin{array}{l}\text { protein kinase C, delta binding protein } \\ {[11 \mathrm{p} 15.4]}\end{array} \\ \text { phosphatase and tensin homolog (mu- } \\ \text { tated in multiple advanced cancers 1) } \\ {[10 \mathrm{q} 23]} \\ \text { prostaglandin-endoperoxide synthase 2 } \\ \text { (prostaglandin G/H synthase and cy- } \\ \text { clooxygenase) } \\ \text { PTGS2 } & \text { [1q25.2-q25.3] } \\ & \text { PYD and CARD domain containing } \\ & {[16 \mathrm{p} 12-11.2]} \\ \text { PYCARD } & \text { retinoic acid receptor, beta } \\ & {[3 \mathrm{p} 24]} \\ \text { RARB } & \end{array}$

RASSF1

Ras association (RalGDS/AF-6) domain family 1 [3p21.3]

\begin{tabular}{|c|c|c|}
\hline $\begin{array}{l}\text { Methylated in } \\
\text { non-tumor lung }\end{array}$ & Methylated in adenocarcinoma & References \\
\hline+ & $\begin{array}{l}\text { More frequently methylated in } \\
\text { tumors. }\end{array}$ & {$[231]$} \\
\hline ND & $\begin{array}{l}6-24 \% \text { methylated in adenocarcin- } \\
\text { oma. }\end{array}$ & {$[232,233]$} \\
\hline+++ & Methylated in $7 / 7$ tumor samples. & {$[50]$} \\
\hline- & $\begin{array}{l}\text { More frequently methylated in } \\
\text { tumors. }\end{array}$ & {$[234]$} \\
\hline $\begin{array}{c}+ \text { Methylated } \\
\text { in } 13-55 \% \\
\text { sputum of } \\
\text { never/heavy smokers. }\end{array}$ & $\begin{array}{l}\text { More frequently methylated in tu- } \\
\text { mors. One report of association } \\
\text { with smoking and late stage. }\end{array}$ & $\begin{array}{l}{[39,90,198,} \\
200,204,220, \\
235-237]\end{array}$ \\
\hline$-/+$ & $\begin{array}{l}\text { More frequently methylated in tu- } \\
\text { mors. } \\
\text { More frequently methylated in } \\
\text { smokers. Correlation shown to age } \\
\text { at which smoking started. } \\
\text { No correlation to stage. One study } \\
\text { shows association with poor } \\
\text { survival. }\end{array}$ & $\begin{array}{l}{[39,105,198,} \\
238] \\
{[38,50,90,} \\
96,204,195, \\
200,220, \\
239-242]\end{array}$ \\
\hline+ & $\begin{array}{l}\text { More frequently methylated in } \\
\text { tumors. }\end{array}$ & [243] \\
\hline+ & $\begin{array}{l}\text { More frequently methylated in tu- } \\
\text { mors. Methylation more frequent in } \\
\text { non-smokers than smokers. }\end{array}$ & {$[105,244]$} \\
\hline++ & $\begin{array}{l}\text { More frequently methylated in } \\
\text { tumors. }\end{array}$ & [245] \\
\hline$-/++$ & $\begin{array}{l}\text { More frequently methylated in tu- } \\
\text { mors. No correlation with tumor } \\
\text { stage. }\end{array}$ & {$[98,238]$} \\
\hline ND & $\begin{array}{l}\text { Infrequently methylated, more } \\
\text { likely mutated. }\end{array}$ & {$[130,132]$} \\
\hline++ & $\begin{array}{l}\text { More frequently methylated in } \\
\text { tumors. }\end{array}$ & [246] \\
\hline+ & $\begin{array}{l}\text { More frequently methylated in tu- } \\
\text { mors, and correlated with poor } \\
\text { survival. }\end{array}$ & [247] \\
\hline++ & $\begin{array}{l}\text { More frequently methylated in tu- } \\
\text { mors, not correlated with poor } \\
\text { survival. }\end{array}$ & {$[248]$} \\
\hline++ & $\begin{array}{l}\text { More frequently methylated in } \\
\text { tumors. }\end{array}$ & {$[50]$} \\
\hline- & $12-15 \%$ methylated in tumors. & [249] \\
\hline
\end{tabular}




$\begin{array}{llll}\begin{array}{l}\text { Locus } \\ \text { (HUGO Name) }\end{array} & \begin{array}{l}\text { Locus description [chromo- } \\ \text { somal location] } \\ \text { an intracellular domain } \\ {[8 \mathrm{p} 22-\mathrm{p} 21]}\end{array} & \begin{array}{r}\text { Table 1, continued } \\ \text { Methylated in } \\ \text { non-tumor lung }\end{array} & \text { Methylated in adenocarcinomd } \\ \text { WIF1 } & \begin{array}{l}\text { WNT inhibitory factor 1 } \\ {[12 \mathrm{q} 14.2]}\end{array} & ++ & \text { More frequently methylated in tumors. } \\ \text { WWOX } & \begin{array}{l}\text { WW domain containing oxidoreductase } \\ {[16 q 23.3-q 24.1]}\end{array} & + & \begin{array}{l}\text { Frequently methylated in squamous cell } \\ \text { cancer, adeno was not examined. }\end{array} \\ \text { ZMYND10 } & \begin{array}{l}\text { zinc finger, MYND-type containing } 10 \\ {[3 \mathrm{p} 21.3]}\end{array} & \begin{array}{l}\text { 30\% methylated in tumors. No correla- } \\ \text { tion with stage. }\end{array}\end{array}$

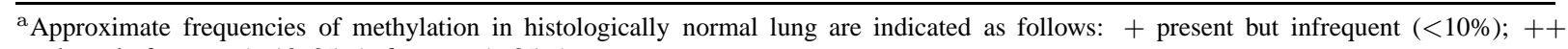
moderately frequent $(\sim 10-25 \%)$; frequent $(>25 \%)$.

${ }^{\mathrm{b}}$ Data given refers to lung adenocarcinoma, unless otherwise indicated.

searchers try to identify methylation caused by environmental influences such as smoking. Using the sensitive and quantitative MethyLight technology, we have also found substantial methylation in histologically normal lung from patients operated for non-cancer reasons, such as lung collapse or emphysema [50]. Low levels of APC methylation were found in 9/11 non-tumor lung samples from non-lung cancer patients, while elevated MTHFR methylation was found for almost all nontumor lung and adenocarcinoma samples. RASSF1 showed modest methylation in $50 \%$ of non-tumor lung samples. CDKN2A methylation was found in $8 / 11$ non-tumor lung samples. In the absence of information on smoking, it is unclear whether the observed methylation in non-tumor lung could be environmentally induced or simply is a consequence of age-dependent methylation. However, the very low levels of APC methylation observed in mesothelioma suggest that if age is crucial, its effects vary per tissue type. Indeed, in the autopsy analysis of different tissues, APC was differentially methylated in different parts of the digestive tract [105]. It is conceivable that age-related methylation plays a part in cancer development, perhaps as an added risk factor. Indeed, many lung cancer patients are over age 65 . In the case of young, non-smoking adenocarcinoma patients, clearly other mechanisms must be at work.

Given the early abundance of hypermethylation in preneoplastic lung, one could wonder whether there is any evidence for early demethylation of $\mathrm{CpG}$ islands. While hypomethylation of certain genes has been observed (see below), it appears to be much less common than hypermethylation, which has been shown to occur widely at $\mathrm{CpG}$ islands throughout the genome [28, 29]. A prominent example of cancer-specific local demethylation is the reactivation of so-called cancer testes (CT) antigens. These are genes that are normally only expressed in the human germline, but become active in certain cancers, such as melanoma, bladder, liver and lung cancer (reviewed in [106]). Some CT genes are X-linked, and others are spread over the autosomal chromosomes. Aberrant expression of these genes frequently coincides with loss of $\mathrm{CpG}$ island methylation [106]. In an immunohistochemistry study of $12 \mathrm{CT}$ antigens in lung cancer, $68 \%$ of adenocarcinomas showed expression of one or more gene, but no expression was evident in adjacent histologically normal lung [107]. However, a different study found hypomethylation and expression of CT antigens in up to half of the normal lung samples adjacent to tumors, and up to $60 \%$ of normal bronchial epithelium from previous smokers [108]. The discrepancy between these two studies might arise from the use of the more sensitive RT-PCR approach in the latter study. In support of the early activation of CT antigen genes, a study of sputum showed hypomethylation of the MAGE CT antigens in up to $24 \%$ of cytologically normal samples [109]. Thus CT antigen re-expression appears to be a very early event that may play a role in field defects. It might provide cells with properties that aid dedifferentiation, proliferation or survival [106].

In conclusion, it appears that many (epi)genetic alterations are found in non-cancer lung (Fig. 2). Some of these changes may be associated with aging, while others are likely consequences of environmental exposures. Irrespective of their etiology, such changes could promote lung cancer development. $\mathrm{LOH}$ and $\mathrm{CpG}$ island hypermethylation appear to be common events that may even target the same gene at different times. For example, FHIT, a candidate tumor suppressor seen to be lost in tumors through $\mathrm{LOH}$ at $3 \mathrm{p} 14.2$, does not show LOH in AAH. However, this does not mean the gene is not inactivated at an early stage; methylation of this locus is seen in lavage fluid from cancer-negative 


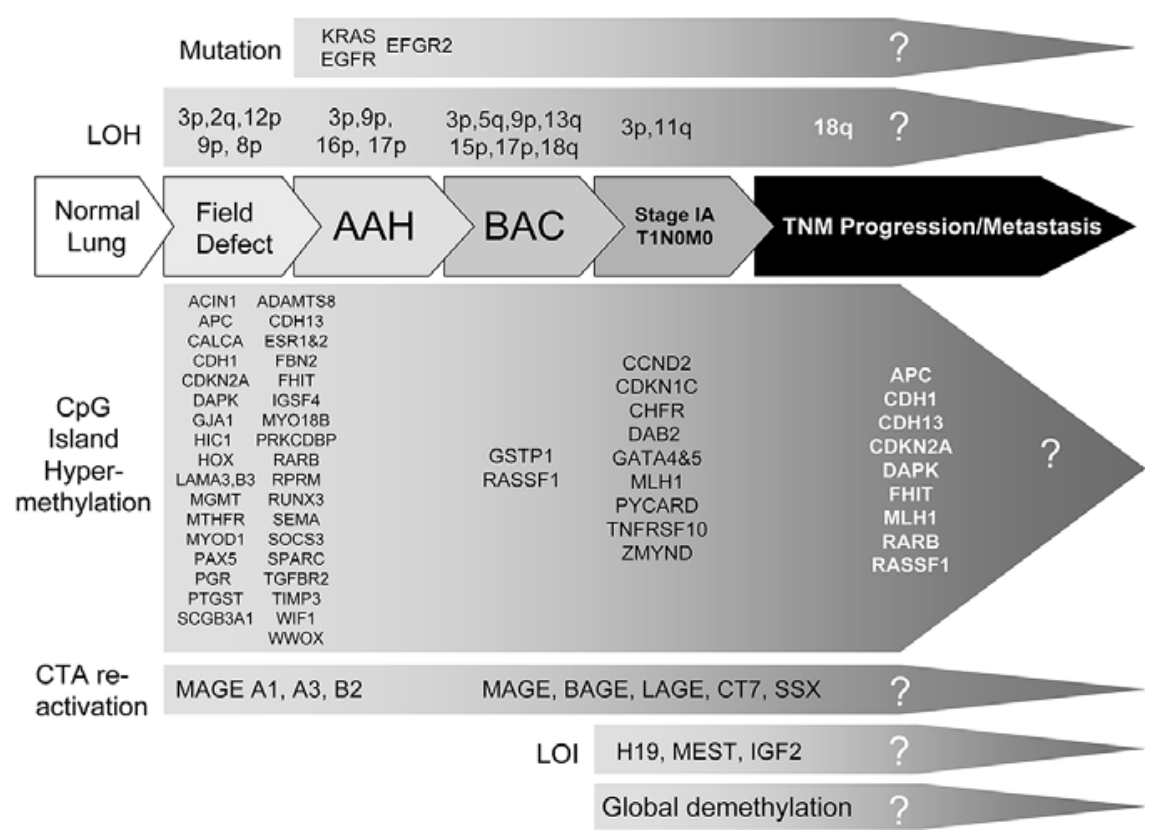

Fig. 2. A framework for sequential (epi)genetic changes during development and progression of lung adenocarcinoma. The progressive stages of lung adenocarcinoma development are indicated by a schematic consisting of overlapping arrows at the center. A partial list of genetic alterations (LOH and mutations) are indicated above, and epigenetic alterations are marked below this schematic. (Epi)genetic lesions are marked above or below the approximate stage of cancer development where they are first seen. It should be noted that this list does not aim to be complete, but is intended to show the diversity of changes and the fact that many changes occur early during adenocarcinoma development. Hypermethylated loci are listed only once in the black text area, even if the methylation frequency increases at later times. The identity of many (epi)genetic alterations remains to be discovered, as indicated by the question marks. Changes known to affect progression (late stage, large tumor size, metastasis and/or poor survival) are marked in white. Loci for which hypermethylation is associated with progression are listed to the right in white text.

cases [110]. Expression of CT antigens is also an early event seen in histologically normal lung. This might lead to alterations in proliferation and differentiation, perhaps providing cells with cancer stem cell-like properties. Loss of growth control would be further supported by decreased expression of cell cycle regulator CDKN2A, whose methylation appears to be a very early event. Decreased CDKN2A expression would bypass the need for mutations of RB1 (which functions downstream). Indeed, RB1 mutations are infrequently seen in lung adenocarcinoma [111,112] and seem to be mutually exclusive with CDKN2A alterations [113115]. Age- or environmentally-induced APC methylation could lead to activation of the WNT pathway and further stimulation of growth through induction of genes such as MYC. Together, these changes would set the stage for the development of foci of AAH. Clearly, much remains to be learned about changes in histologically normal lung, and it would be of great interest to establish detailed methylation profiles from a large number of cases, to compare the results of methylation profiles in tumors and adjacent non-tumor lung from the same subjects, and to correlate methylation levels to environmental exposures. Further studies of lung from non-cancer subjects with varying degrees of environmental exposures would also contribute importantly to insights into the role of aging and the environment. Detailed insights into the molecular changes seen in histologically normal lung will be of great use for the development of chemoprevention strategies. Given the prominent presence of hypermethylation early in the process of adenocarcinoma development, delivery of chemopreventive methylation inhibitors may be one avenue of clinical research worth exploring.

\section{5. (Epi)genetic changes in $\mathrm{AAH}$}

Immunological characterization of AAH shows increased staining of TP53, cyclin D1 (CCND1) and the anti-apoptotic protein Survivin (BIRC5), and a decrease in CDKN2A and CDKN1B expression [51,116118]. However, immunological analysis does not shed light on the mechanism by which such aberrant expression is achieved. Molecular examination of AAH at the level of DNA is challenging due to the limited 
size of these lesions, which are generally smaller than $5 \mathrm{~mm}$ and contain few cells due to their alveolar structure [51]. For this reason, the (epi)genetic analysis of AAH is still quite limited. Most studies to date have focused on examining $\mathrm{LOH}$ and a limited set of mutations in proto-oncogenes and tumor suppressors [51]. To our knowledge, no studies of DNA methylation in AAH have been published.

Based on the occurrence of $\mathrm{LOH}$ in histologically normal lung one might expect overlapping and progressive losses in AAH. Indeed, when compared to histologically normal adjacent lung, AAH shows LOH of distinct regions of chromosomes $3 p, 9 p, 16 p$ and $17 p$ [119-121]. Loss of 9p was found in AAH in 7-33\% of cases, and in some reports became more frequent as the lesions progressed to adenocarcinoma [119,122]. As in adjacent non-tumor lung (above) these losses are thought to happen sequentially, targeting distinct regions at different times. For example, FHIT, although located in a chromosomal region commonly showing LOH (3p14.2), does not appear to be deleted in AAH; LOH is not evident until BAC and adenocarcinoma [123,124].

Interestingly, in over half of the cases of LOH in $\mathrm{AAH}$, the $9 \mathrm{p}$ region included the TSC1 locus [121]. In addition, $22 \%$ of AAH showed loss of $16 \mathrm{p}$, and $6 \%$ of these were in $16 \mathrm{p} 13.3$, the location of TSC2. The TSC genes are of substantial interest because their proteins form a negative regulatory complex in the PI3K pathway, which mediates signals from growth factor/hormone/cytokine receptors to the FRAP1 (mTOR) pathway. FRAP1 plays a powerful role in the control of cell growth by modulating the levels of mRNA translation and proliferation $[125,126]$. Inherited mutations of TSC1 cause mental retardation and a host of other effects, including AAH-like lesions in the lung. The link between TSC genes and AAH is further strengthened by the observation that adenocarcinomas showing $\mathrm{LOH}$ at TSC1 or TSC2 frequently show AAH [127]. A search for mutations in the two TSC genes in AAH showed these were uncommon [128], but to our knowledge, hypermethylation of TSC1 and 2 promoter $\mathrm{CpG}$ islands, which can occur in breast cancer [129], has not been examined in lung cancer. Another gene in the FRAP1 pathway is tumor suppressor LKB1, which functions upstream of TSC1/TSC2. Germline mutations in LKB1 predispose to a variety of cancers, including occasional lung adenocarcinomas. Mutations in LKB1 have been found in $30 \%$ of sporadic adenocarcinoma [130], and loss of LKB expression is seen 5\% of low grade $\mathrm{AAH}$, and $21 \%$ of high grade $\mathrm{AAH}$ [131].
Methylation of LKB1, which is infrequent in adenocarcinoma [132], is not the mechanism for LKB1 inactivation. Other changes are also seen in the translational regulatory pathway during the evolution of normal cells to $\mathrm{AAH}, \mathrm{BAC}$, and beyond, such as a progressive increase in eukaryotic initiation factor 4E (EIF4E) [133]. Thus, increased translation appears to be a hallmark of developing adenocarcinoma.

As the cells that make up AAH lesions increase their translation and thus their protein output, it seems likely that their cell cycle would also be deregulated. A decrease in CDKN2A expression has been observed in AAH [118]. CDKN2A already shows methylation in histologically normal lung (Table 1), but does methylation increase in $\mathrm{AAH}$ to further reduce cell cycle control? We have recently carried out a study of four cases, comparing CDKN2A methylation in AAH with matched associated adenocarcinoma and non-tumor lung. Preliminary data obtained using the quantitative methylation assay MethyLight [134,135] showed that, as expected, CDKN2A was somewhat methylated in all four samples of histologically normal lung. In three out of four matched AAH lesions and in all matched adenocarcinoma samples, the level of methylation was more than twice as high (Galler, Kerr and Laird-Offringa, unpublished results). This suggests that further silencing of CDKN2A occurs as lung cells progress to AAH lesions.

In addition to molecular changes that promote cell cycle transitions, changes affecting the response to growth signals might also be early events that occur in AAH. RAS proteins play a role in mediating receptor tyrosine kinase signaling. KRAS mutations are found in $14-30 \%$ of lung adenocarcinomas [136-138]. Such mutations have also been observed in AAH lesions [55, 56,139]. In support of the idea that KRAS activation is an early event, it was noted that these mutations are present in adenocarcinomas from longtime smokers as well as tumors from patients who had quit smoking many years ago, but are absent in adenocarcinomas from non-smokers [136].

Activation of the receptor tyrosine kinase signal transduction pathway is one of the growth stimulatory changes seen in lung adenocarcinoma, but KRAS mutations are only found in a limited percentage of cases. This suggests that alternative molecular changes might be found in cells lacking activated RAS. One strong candidate is mutation of the epidermal growth factor receptor (EGFR), a gene activation event that has received much recent publicity because it sensitizes lung cancers to treatment with certain tyrosine kinase in- 
hibitors (reviewed in [138]). Tyrosine kinase receptors signal through RAS, so that the action of these two genes converges. Interestingly, EGFR mutations appear to be more common in the lung cancers of Asian non-smoking women, the same group that shows a link with HPV infection. As would be expected, EGFR and KRAS mutations appear to be mutually exclusive [138]. A recent examination of the methylation status of 5 genes and EGFR and KRAS mutations [140] confirmed this observation, and in addition, showed an inverse relationship between EGFR mutations and methylation of CDKN2A and CHD13 (adhesion molecule H-cadherin). What is the status of EGFR mutations in AAH? The reported percentage of lesions with such a change varies from 3 to $40 \%$ [141,142]. This variability may be related to differences in etiology of the examined samples; AAH from the lungs of nonsmokers exposed to HPV would be much more likely to show EGFR mutations, and lack CDKN2A methylation since HPV protein E7 inactivates RB1 [143]. Based on the previously shown association, $\mathrm{CDH} 13$ methylation may also be less likely in these patients, though the mechanistic link to EGFR mutations is not yet clear. In contrast, smokers would be more likely to show KRAS activation and CDKN2A methylation [140]. If true, this would suggest that there may be at least two parallel molecular pathways to the initiation of lung adenocarcinoma. However, whether CDKN2A methylation is associated with KRAS mutations is controversial $[140,144,145]$. It will be interesting to determine whether there are epigenetic changes that deregulate the RAS pathway. Inactivation of the mismatch repair gene MGMT might indirectly facilitate the acquisition of RAS mutations in certain types of cancer. Although one report found that MGMT methylation is relatively infrequent in early lung adenocarcinoma lesions [146], we found methylation of MGMT in the cancer-free lung of 8/10 patients operated for non-cancer reasons, and in 7/7 lung adenocarcinomas [50]. Early MGMT inactivation could markedly promote the acquisition of mutations.

In summary, a limited set of molecular changes in AAH have been characterized (Fig. 2). A number of these changes consist of progression of alterations already visible in non-tumor lung, such as further $\mathrm{LOH}$ and methylation of CDKN2A. Certain changes are new, such as mutations in KRAS and EGFR. For many of the well characterized (epi)genetic changes observed in adenocarcinoma, it remains unclear whether they occur in AAH or not. The challenge in studying these lesions is their limited availability and their very small size. While immunological staining is feasible and offers detailed insight into molecular alterations as they relate to morphology, this approach requires individual sections for each analysis. The isolation of DNA from microdissected lesions might provide a higher yield of molecular information, potentially allowing the analysis of several loci per section. A very interesting alternative approach to the identification of AAHspecific (epi)genetic alterations was pioneered by Shimada and colleagues, who compared a cell line derived from an AAH lesion (PL16T) with its normal counterpart (PL16B) [147]. A screen for hypermethylated loci yielded ACIN1, apoptotic chromatin condensation inducer 1 , which was differentially methylated between the two cell lines [148]. Examination of 37 tumors and paired adjacent non-tumor control tissue showed that ACIN1 was more frequently methylated in BAC/adenocarcinomas than in histologically normal tissue. Further examination of (epi)genetic differences between the two cell lines could provide additional clues to AAH-specific deregulatory events, but this approach would be more powerful if additional AAHbased cell lines were established. A concern is whether these cells will maintain their AAH characteristics. As we await more data from the cell line approach, the collection and analysis of numerous AAH lesions, with analysis of a limited number of markers at a time, will provide slow but progressive insight into (epi)genetic alterations that occur during this preneoplastic stage of adenocarcinoma development. Such findings will be of high relevance for the development of early detection and chemoprevention strategies.

\section{6. (Epi)genetic changes during progression from AAH to adenocarcinoma}

As AAH lesions grow and become more atypical, losing their characteristic structure, they become indistinguishable from BAC [149]. Changes in cell-cell contacts are illustrated by incremental loss of expression of CDH1 (encoding E-cadherin, a membrane glycoprotein thought to play a role in adhesion). CDH1 is expressed in $\mathrm{AAH}$ but begins to decline in BAC, with further loss of expression in adenocarcinoma [150]. Matrix metallopeptidases (MMPs) become elevated in the BAC part of mixed adenocarcinoma/BAC lesions [151], hinting at the acquisition of invasive properties. A gradual increase in proliferation markers, such as components of the telomere complex and translation initiation factor eIF4E is seen as lesions progress 
from $\mathrm{AAH}$ to $\mathrm{BAC}$, and then to adenocarcinoma [62, 133,152]. These observations indicate that changes associated with growth deregulation can progress as the lesion develops from high grade AAH into BAC. LOH continues to become more evident. An analysis of adenocarcinomas with BAC component (used because true non-invasive BAC is rare) showed frequent $5 q$ and $17 p$ losses in what would be considered the lowest grade sections of the tumors [153]. A detailed investigation of loci associated with $\mathrm{LOH}$, using BACs and small adenocarcinomas, showed localized loss of 5q(APC), 9p(CDKN2A), 13q(RB1), 17p(TP53) and $18 \mathrm{q}$ (SMAD4) in BAC, while LOH of $3 \mathrm{p}$ (FHIT) and $11 \mathrm{q}(\mathrm{INT} 2)$ did not become prominent until invasion [154], consistent with the observed persistence of FHIT protein expression in AAH and BAC but loss of expression in invasive disease [124]. The late loss of FHIT is interesting in light of the observation of methylation of this locus in lavage fluid from cancer-negative cases [110], hinting at the potential for genes to become inactivated by different mechanisms at different times. In the case of CDKN2A, biallelic inactivation through LOH combined with hypermethylation was seen in $22 \%$ of adenocarcinomas, providing a mechanism for progressive CDKN2A deregulation [155].

One alteration seen in high grade AAH/BAC is EGFR2/HER2 expression [156]. Like EGFR mutations, mutations in EGFR2 are found most commonly in adenocarcinoma from female Asian non-smokers, and are mutually exclusive with KRAS alterations [138, 157]. The observed elevated EGFR2 expression in AAH/BAC suggests that the tyrosine kinase signaling pathway is altered by a variety of mechanisms before adenocarcinoma reaches its invasive stage. The methylation of DNA repair gene MGMT, which is seen in histologically normal lung but increases in frequency to $28 \%$ in pure BAC, could potentially facilitate the acquisition of further genetic hits in this and other pathways [158]. As can be seen in Table 1, many other loci that show some frequency of methylation in histologically normal lung adjacent to adenocarcinoma show more frequent methylation as adenocarcinoma develops. This includes genes involved in the cell cycle, DNA repair, differentiation, cell-cell contacts and adhesion, and signaling. In addition, loci for which methylation in histologically normal lung has not been seen, such as cell cycle control genes CCND2 and CHFR, signaling molecules DAB2 and TNFRSF10 $\mathrm{C}$ and D (trail decoy receptors), transcription factors GATA4 and 5, and DNA repair gene MLH1, now show methylation (Fig. 2). The widespread methylation ob- served in lung adenocarcinoma speaks to the crucial role epigenetic alterations play in the development and progression of this disease. Considering that only a very small fraction of the approximately $30,000 \mathrm{CpG}$ islands in the genome [159] has been examined, much further information remains to be gathered. The use of high throughput and epigenomic approaches will greatly accelerate the accrual of information about epigenetic alterations in lung adenocarcinoma [35,134, 135,160]. Among a variety of new approaches, the use of $\mathrm{CpG}$ island microarrays is considered to be one of the most powerful ones; it can be used to examine the methylation status of thousands of genes simultaneously [160]. With the application of this and other techniques, rapid progress in the identification of DNA methylation changes can be expected in the coming years.

\section{7. (Epi)genetic changes during progression to metastasis}

It is usually the metastatic spread of cancer, not the primary lesion, that is the cause of cancer death. Thus, the investigation of (epi)genetic alterations that enable metastasis is crucially important. Successful metastasis not only depends on the ability of cancer cells to escape from the initial site, but also to survive and proliferate in the new location [161,162]. Evidence indicates that the local environment has a strong influence on the ability of metastatic cells to grow. It has been proposed that micrometastases might lie dormant until particular metastasis-suppressing genes are lost or inactivated [161,162]. Whether this is true for lung cancer remains a question, though some data in support of this idea has been provided. A recent examination of the prognostic significance of lung cancer patient nodes carrying either isolated tumor cells, micrometastases $(<0.2 \mathrm{~mm})$, or lesions $\geqslant 0.2 \mathrm{~mm}$ showed that patients with nodes positive for isolated tumor cells or micrometastases did not exhibit a shorter survival than node-negative cases [163]. The number of cases examined in the study were relatively small (60 patients), so that the results should be interpreted with caution, but the observations hint at the potential requirement for additional genetic and/or epigenetic changes to allow metastases to flourish in their new location. These metastasis-specific molecular changes could consist of the inactivation of metastasis suppressor genes or the activation of genes that promote proliferation. There are at least two striking examples of genes that un- 
dergo opposing alterations to promote both metastasis and proliferation. One example is CD44, encoding the hyaluronic acid receptor, a protein that mediates cellcell and cell-matrix interactions [164]. Increased expression of CD44 promotes metastasis, while reduced expression promotes local growth. The inherent reversibility of DNA methylation makes this mechanism of gene (in)activation particularly suited for inversions of gene deregulation during metastasis. A second example is provided by CDH1. Increased methylation and reduced expression of $\mathrm{CDH} 1$ favors metastasis, while reduced methylation and increased expression favors growth $[165,166]$. These examples illustrate that the role of DNA methylation in metastasis can be highly complex.

What is known about methylation-based (in)activation in lung adenocarcinoma to date? The frequency of methylation of several loci is linked to progression (Table 1, Fig. 2). Hypermethylation of APC, CDH1, CDH13, CDKN2A, DAPK, FHIT, MLH1, RARB, and RASSF1 in adenocarcinoma has been associated with larger tumor size, late stage, poor survival, and/or nodal metastases (Table 1). Indeed, the number of methylated genes in a given tumor sample has been shown to be correlated with the presence of brain metastases from primary melanomas, breast cancers and lung carcinomas [167]. In addition to methylation of the well known genes listed above, it is likely that the inactivation of previously unmethylated loci encoding metastasis suppressor genes will play a role in the ability of tumors to spread to secondary sites. Metastasis suppressor genes have been identified in different kinds of cancer [161, 162] and are defined as genes that "encode proteins that specifically suppress metastasis formation while having no discernable effect on primary tumor growth" [162]. Examples are osteoblast cadherin (CDH11 [168]), nonmetastatic gene family members (eg. nm23 genes such as NME2 [162]), and ribonucleotide reductase M1 subunit (RRM1 [169]). To our knowledge, none of these markers have been evaluated for hypermethylation in lung cancer.

Just as inactivation of a variety of genes could promote metastasis, increased expression of others could be required. This can be achieved through epigenetic mechanisms, as illustrated by the observation that treatment of cancer cells with the DNA methylation inhibitor 5-azacytidine promotes micrometastais formation [170,171]. Hypomethylation of the neuronal synuclein-gamma gene is linked to metastasis of diverse human tumors, including lung cancer [172]. Reexpression of cancer testes antigens could also con- tribute in a variety of ways to metastatic potential [106]. Understanding the mechanistic complex of methylation to metastasis will require extensive further investigation.

\section{DNA methylation as a marker for lung adenocarcinoma diagnosis and prognosis}

While it will take many more years before the mechanistic roles of (epi)genetic changes in lung adenocarcinoma development and progression are understood, in the short term, simply cataloging such changes could provide valuable diagnostic and staging tools. Genetic alterations can be just as informative as epigenetic ones, however, the analysis of promoter $\mathrm{CpG}$ island hypo/hypermethylation as a cancer marker has several important advantages. The first is that the alteration is clearly localized. Mutations that activate or inactivate proteins can be located in many different regions of a gene (with the exception of certain cases in which very specific amino acids are altered, such as the RAS genes), necessitating the examination of large sections of sequence. In contrast, the $\mathrm{CpG}$ islands of interest largely lie near the transcription start site of genes. This allows the rapid genome-based design of probes and primers that can provide accurate measures of methylation for any locus of interest. A second advantage is that methylation alterations are not an all or nothing phenomenon. They can be present to variable degrees and with variable frequencies for different loci. Thus, they can provide a richness of information about a locus that is unparalleled, except perhaps by gene expression analysis. Quantitative methylation analysis can be used to compare levels of methylation in different tissues or in similar tissues under different conditions [135]. Thirdly, DNA methylation information is robust; it is well maintained in archival specimens. Although prolonged storage of archival specimens can result in severe fragmentation of DNA, using MethyLight [134], we have been very successful in obtaining methylation information from paraffin-embedded material that was over ten years old (Laird-Offringa laboratory, unpublished data). DNA methylation information is also relatively stable in biological fluids from patients. Many studies have demonstrated that methylation data can be reliably obtained from a variety of bodily fluids, including sputum, serum, urine, and stool [30,173,174]. Thus, analysis of DNA methylation can be used for retrospective studies using archival collections, as well as for the examination of fresh biological specimens 
from cancer patients. Fourth, DNA methylation can be very sensitively detected, either by real-time PCR or nested PCR of bisulfite-treated DNA. (Bisulfite treatment incorporates the methylation information into the DNA sequence, by converting unmethylated Cs to U, while leaving methylated Cs intact [175]). Fifth, the availability of $\sim 30,000 \mathrm{CpG}$ islands allows the development of many different markers that can be simultaneously assessed on the same platform. Thus, methylation markers can be easily combined into panels that could increase sensitivity and specificity.

One key consideration in the application of DNA methylation analysis as a marker for cancer is the fact that, like any biomarker, it is used for a comparative analysis. The choice of compared tissues must be carefully weighed to provide information relevant to the intended application. Such applications could be cancer detection, disease monitoring, cancer staging, detection of premalignant lesions, cancer classification, or prognostication. One very promising application of methylation markers is their use as a complement to low-dose spiral computed tomography (LDSCT), which can provide detailed images of the lung. LDSCT has been advocated for the screening of subjects at risk for lung cancer (long term heavy smokers), and several pilot studies have explored its potential for early detection $[176,177]$. However, LDSCT detects pulmonary nodules in up to $50 \%$ of subjects, less than $5 \%$ of which will prove to be malignant, and thus could result in overdiagnosis $[176,178,179]$. Visual interpretation of LDSCT scans is improving, in particular in Japan where screening has been advocated for some time [180], but its accuracy remains limited. Resections are invasive procedures that should be carried out only when they clearly benefit the patient (usually limited to NSCLC stages I, II and occasionally IIIA) [178]. Fine needle aspirates may be used to obtain tumor material for diagnosis, but yields may be low and the reliability of the obtained sample is highly dependent on the ability to accurately locate the biopsy area. Great benefit could be derived from the availability of non-invasively obtainable molecular markers. To this end, methylation signatures could be detected in exfoliative material (sputum, bronchioalveolar lavage, bronchial brushings) or in plasma or serum [31]. It has been demonstrated that tumor DNA from lung cancer patients can be found in exfoliative material [91-94,181] and in the blood of a substantial fraction of cancer patients [182-184]. Because they are DNA-based, methylation markers can be amplified by PCR, and thus provide considerable sensitivity, in particular when quantitative methods are used [31,94,135,160]. However, before methylation markers can be used to complement LDSCT, markers or marker panels with high sensitivity and specificity must be identified.

For the identification of the type of strictly cancerspecific methylation markers that could be used to complement visual lung cancer screening by spiral CT, one would initially compare tumor tissue with histologically normal adjacent tissue from the same patient. This exquisitely controls for environmental exposures and individual genetic variation. Differentially methylated loci identified in this manner are strong candidates for cancer-specific markers. Promising loci could then be further evaluated by comparing methylation levels in patients' bodily fluids (serum, plasma, bronchioalveolar lavage, sputum, exhaled air condensate) to those in similar fluids from subjects with similar exposures but without cancer. This would provide an indication of their clinical sensitivity and specificity. In the case of lung cancer methylation markers, ideally one would identify markers that are specific for every histological subtype of lung cancer, and that can also distinguish between primary lung cancer and metastases to the lung from primary cancers elsewhere in the body. This would allow visually detected lung cancer lesions to be identified not only as primary lung cancer but potentially also as a particular histological subtype.

To develop markers for the detection of precancerous alterations, DNA methylation from a variety of biological specimens (histologically normal, premalignant or cancerous lung, bodily fluids) would be compared between subjects with and without cancer, and differing in their environmental exposures. This approach has been carried out by many, and has provided cancer risk indicators $[30,31,94]$. An example of an exciting recent study is the examination of 14 loci in the sputum of a high-risk lung cancer cohort. Six loci (CDKN2A, DAPK, GATA5, MGMT, PAX5 and RASSF1) were associated with an increased cancer risk, and methylation of three or more of these genes showed a $65 \%$ sensitivity and specificity for lung cancer [94]. Although sensitivity and specificity are not yet optimal, studies such as this one provide an indication of the strong potential of DNA methylation markers for lung cancer detection and risk assessment.

Obtaining lung biopsy samples from healthy individuals is challenging, so that focusing on other types of samples that are obtained through less invasive means would be useful. Bronchioalveolar lavage and sputum are an option (although non-smokers will be less able to provide any sputum), but blood (serum or plasma) 
might be a better choice. We are not aware of attempts to measure DNA methylation in exhaled breath condensate, but this may also be worth exploring. By using markers for precancerous lesions to screen at-risk subjects, individuals identified as high risk could be followed more closely, or could be subjected to chemoprevention strategies as they become available. If they are smokers, they should of course be strongly encouraged to stop smoking.

Development of methylation markers as prognostic indicators for survival of lung cancer patients, or for prediction of response to therapy, will require the analysis of DNA methylation profiles of large cohorts of patients and comparison of their clinical variables. To date, while some correlations to prognosis have been found (see Table 1), it would appear that the optimal prognostic markers have not yet been uncovered. Epigenomic comparisons of primary tumors with their corresponding metastatic lesions may be a powerful way to identify node-specific metastasis markers. Such markers would also be useful for staging, through the molecular analysis of sampled nodes. A recent study of node micrometastases in NSCLC patients using promoter hypermethylation assays from fine needle aspirates showed an increase in sensitivity but a loss of specificity when the molecular data was added to conventional cytology assays [185]. More nodes were scored as positive, but these nodes did not necessarily lead to progression, as measured by clinical outcome [185]. This could happen if the markers used were not metastasis-specific. Tumor-specific markers would also identify potentially dormant micrometastases, and thus would reduce specificity, whereas markers that occur only in successful metatstatic growth (in nodes or elsewhere) would provide true metastatic indicators. Besides node-specific metastatic indicators, it should be possible to identify metastatic markers that are present in the primary tumor. Obtaining such markers is more challenging, as tumors that metastasize need to be compared with tumors that do not. Since they are not obtained from the same patient, these comparisons are not optimally controlled for genetic variation and different environmental exposures (in contrast to comparisons between primary tumors and metastases from a single patient). Once such markers are obtained, they could be applied to accurate staging, as a substantial fraction of early stage adenocarcinoma patients (T1N0 or T2N0) later relapse with the development of nodal and / or visceral metastases [186-190].

\section{Conclusion}

From the sections above, it should be apparent that while much information has been gained, we are still at the very beginning of understanding the mechanistic implications of DNA methylation alterations in lung cancer, of cataloging these changes, and of applying them to the clinic. The advent of high throughput and epigenomic approaches promises rapid progress in the identification of methylation changes. However, the evaluation of the mechanistic and clinical implications of such changes will take many years. This is an incredibly exciting time to study DNA methylation in lung cancer, as it will be possible to make huge strides forward in many areas. Our understanding of lung cancer etiology will be aided by the identification of genes activated or silenced by methylation changes, and by exploring correlations with environmental factors such as smoking and viral infection. DNA methylation markers for diagnosis, classification and prognostication could be tremendously beneficial in the clinic, and could be applied to early detection, the determination of treatment strategies and to the assessment of treatment efficacy. When properly applied, DNA methylation markers could save thousand of lives in the foreseeable future.

\section{Acknowledgements}

The authors would like to thank members of the Laird and Laird-Offringa labs for their constructive criticisms and support. Much of the work cited in this review would not have been possible without the generous participation of lung cancer patients, at risk subjects, and /or control subjects, who have selflessly donated their tissues and other specimens to lung cancer research. Here, we would like to acknowledge their important contributions. Support from the following funding agencies is acknowledged: The Whittier Foundation for Translational Research and the National Institutes of Health/National Cancer Institute (R21 CA102247) for JSG, PWL and IALO. Ite Laird-Offringa and Peter Laird are both shareholders in Epigenomics, AG, a company aimed at developing methylation markers for cancer. None of the work in the Laird or LairdOffringa labs was supported or in any way controlled by Epigenomics. 


\section{References}

[1] ACS, Cancer facts \& figures-2005. 2005, American Cancer Society: Atlanta.

[2] L.A.G. Ries, M.P. Eisner, C.L. Kosary, B.F. Hankey, B.A Miller, L.X. Clegg, A. Mariotto, E.J. Feuer and B.K. Edwards, eds, SEER Cancer Statistics Review, 1973-1996, National Cancer Institute. Bethesda, MD, http://seer.cancer. gov/csr/1975 2001/, 2004.

[3] A.J. Sasco, M.B. Secretan and K. Sraif, Tobacco smoking and cancer: a brief review of recent epidemiological evidence, Lung Cancer 45(Suppl 2) (2004), S3-S9.

[4] National Center for Health Statistics, Health, United States, 2004. 2004: Hyattsville, MD.

[5] J.O. Ebbert, P. Yang, C.M. Vachon, R.A. Vierkant, J.R. Cerhan, A.R. Folsom and T.A. Sellers, Lung cancer risk reduction after smoking cessation: observations from a prospective cohort of women, J. Clin. Oncol. 21 (2003), 921-926.

[6] W.D. Travis, Pathology of lung cancer, Clin. Chest Med. 23 (2002), 65-81.

[7] W.D. Travis, L.B. Travis and S.S. Devesa, Lung Cancer, Cancer 75 (1995), 191-202.

[8] K.-Y. Chen, C.-H. Chang, C.-J. Yu, S.-H. Kuo and P.-C. Yang, Distribution according to histologic type and outcome by gender and age group in Taiwanese patients with lung carcinoma, Cancer 103 (2005), 2566-2574.

[9] I. Yoshimi, A. Ohshima, W. Ajiki, H. Tsukuma and T. Sobue, A comparison of trends in the incidence rate of lung cancer by histological type in the Osaka Cancer Registry, Japan, and in the Surveillance, Epidemiology and End Results Program, USA, Jpn. J. Clin. Oncol. 33 (2003), 98-104.

[10] M.J. Thun, C.A. Lally, J.T. Flannery, E.E. Clle, W.D. Flanders and C.W.J. Heath, Cigarette smoking and changes in the histopathology of lung cancer, J. Natl. Cancer Inst. 89 (1997), 1580-1586.

[11] S.D. Stellman, J.E. Muscat, D. Hoffmann and E.L. Wynder, Impact of filter cigarette smoking on lung cancer histology, Prev. Med. 26 (1997), 451-456.

[12] N.S. Liu, M.R. Spitz, B.L. Kemp, C. Cooksley, F.V. Fossela, J.S. Lee, W.K. Hong and F.R. Khuri, Adenocarcinoma of the lung in young patients; the M.D. Anderson experience, Cancer 88 (2000), 1837-1841.

[13] Y.C. Chen, J.H. Chen, K. Richard, P.Y. Chen and D.C. Christiani, Lung adenocarcinoma and human papillomavirus infection, Cancer 101 (2004), 1428-1236.

[14] P.A. Jones and P.W. Laird, Cancer epigenetics comes of age, Nature Genet. 21 (1999), 163-167.

[15] P.W. Laird, Oncogenic mechanisms mediated by DNA methylation, Molec. Med. Today 3 (1997), 223-229.

[16] M. Esteller, Epigenetics provides a new generation of oncogenes and tumour-suppressor genes, Br J Cancer 94 (2006), 179-183.

[17] S.B. Baylin, M. Esteller, M.R. Rountree, K.E. Bachman, K. Schuebel and J.G. Herman, Aberrant patterns of DNA methylation, chromatin formation and gene expression in cancer, Hum. Mol. Genet. 10 (2001), 687-692.

[18] A.P. Bird and A.P. Wolffe, Methylation-induced repression belts, braces and chromatin, Cell 99 (1999), 451-454.

[19] M.R. Rountree, K.E. Bachman, J.G. Herman and S.B. Baylin, DNA methylation, chromatin inheritance, and cancer, Oncogene 20 (2001), 3156-3165.

[20] P.A. Jones and S.B. Baylin, The fundamental role of epigenetic events in cancer, Nature Reviews Genetics 3 (2002), 415-428.
[21] P.W. Laird, The Power and the Promise of DNA Methylation Markers, Nature Reviews Cancer 3 (2003), 253-266.

[22] A.P. Bird, CpG-rich islands and the function of DNA methylation, Nature 321 (1986), 209-213.

[23] F. Larsen, G. Gundersen, R. Lopez and H. Prydz, CpG islands as gene markers in the human genome, Genomics 13 (1992), 1095-1107.

[24] D. Takai and P.A. Jones, Comprehensive analysis of CpG islands in the human chromosomes 21 and 22, Proc. Natl. Acad. Sci. USA 99 (2002), 3740-3745.

[25] A.P. Feinberg, R. Ohlsson and S. Henikoff, The epigenetic progenitor origin of human cancer, Nat Rev Genet 7 (2006), 21-33.

[26] P.A. Wade, Methyl CpG binding proteins: coupling chromatin architecture to gene regulation, Oncogene 20 (2001), 3166-3173.

[27] J.P. Issa, CpG-island methylation in aging and cancer, Curr. Top. Microbiol. Immunol. 249 (2000), 101-118.

[28] J.C. Costello, M.C. Fruhwald, D.J. Smiraglia, L.J. Rush, G.P. Robertson, X. Gao, F.A. Wright, J.D. Feramisco, P. Peltomaki, J.C. Lang, D.E. Schuller, L. Yu, C.D. Bloomfield, M.A. Caligiuri, A. Yates, R. Nishikawa, H.J.S. Huang, N.J. Petrelli, X. Zhang, M.S. O'Dorisio, W.A. Held, W.K. Cavenee and C. Plass, Aberrant CpG-island methylation has nonrandom and tumor-type-specific patterns, Nature Genet. $\mathbf{2 5}$ (2000), 132-138.

[29] M. Esteller, P.G. Corn, S.B. Baylin and J.G. Herman, A gene hypermethylation profile of human cancer, Cancer Res. 61 (2001), 3225-3229.

[30] J.A. Tsou, J.A. Hagen, C.L. Carpenter and I.A. LairdOffringa, DNA methylation analysis: a powerful new tool for lung cancer diagnosis, Oncogene 21 (2002), 5450-5461.

[31] S.A. Belinsky, Gene-promoter hypermethylation as a biomarker in lung cancer, Nature Reviews Cancer 4 (2004), $1-11$.

[32] W. Digel and M. Lubbert, DNA methylation disturbances as novel therapeutic target in lung cancer: preclinical and clinical results, Crit Rev Oncol Hematol 55 (2005), 1-11.

[33] E.S. Lander, L.M. Linton, B. Birren, C. Nusbaum, M.C. Zody, J. Baldwin, K. Devon, K. Dewar, M. Doyle, W. FitzHugh, R. Funke and D. Gage, Initial sequencing and analysis of the human genome, Nature 409 (2001), 860-921.

[34] A.P. Feinberg, The epigenetics of cancer etiology, Semin. Cancer Biol. 14 (2004), 427-432.

[35] I.M. Wilson, J.J. Davies, M. Weber, C.J. Brown, C.E. Alvarez, C. MacAulay, D. Schubeler and W.L. Lam, Epigenomics: mapping the methylome, Cell Cycle 5 (2006), 155158.

[36] A.K. Virmani, J.A. Tsou, K.D. Siegmund, L. Shen, T.I. Long, P.W. Laird, A.F. Gazdar and I.A. Laird-Offringa, Hierarchical clustering of lung cancer cell lines using DNA methylation markers, Cancer Epid. Biom. Prev. 11 (2002), 291-297.

[37] S. Toyooka, K.O. Toyooka, R. Maruyama, A.K. Virmani, L. Girard, K. Miyajima, K. Harada, Y. Ariyoshi, T. Takahashi, K. Sugio, E. Brambilla, M. Gilcrease, J.D. Minna and A.F. Gazdar, DNA methylation profiles of lung tumors, Mol. Cancer Therap. 1 (2001), 61-67.

[38] S. Toyooka, M. Suzuki, T. Tsuda, K.O. Toyooka, R. Maruyama, K. Tsukuda, Y. Fukuyama, T. Iizasa, T. Fujisawa, N. Shimizu, J.D. Minna and A.F. Gazdar, Dose effect of smoking on aberrant methylation in non-small cell lung cancers, Int. J. Cancer 110 (2004), 462-464.

[39] S. Toyooka, R. Maruyama, K.O. Toyooka, D. McLerran, Z. Feng, Y. Fukuyama, A.K. Virmani, S. Zochbauer-Muller, 
K. Tsukuda, K. Sugio, N. Shimizu, K. Shimizu, H. Lee, C.-Y. Chen, K.M. Fong, M. Gilcrease, J.A. Roth, J.D. Minna and A.F. Gazdar, Smoke exposure, histologic type and geography-related differences in the methylation profiles of non-small cell lung cancer, Int. J. Cancer 103 (2003), 153-160.

[40] S. Zochbauer-Muller, J.D. Minna and A.F. Gazdar, Aberrant DNA methylation in lung cancer: biological and clinical implications, Oncologist 7 (2002), 451-457.

[41] J.M. Nigro, K.R. Cho, E.R. Fearon, S.E. Kern, J.M. Ruppert, J.D. Oliner, K.W. Kinzler and B. Vogelstein, Scrambled exons, Cell 64 (1991), 607-613.

[42] E.R. Fearon and B. Vogelstein, A genetic model for colorectal tumorigenesis, Cell 61 (1990), 759-767.

[43] M. Guo, M.G. House, C. Hooker, Y. Han, E. Heath, E. Gabrielson, S.C. Yang, S.B. Baylin, J.G. Herman and M.V. Brock, Promoter hypermethylation of resected bronchial margins: a field defect of changes? Clin Cancer Res 10 (2004), 5131-5136

[44] B.J. Braakhuis, M.P. Tabor, J.A. Kummer, C.R. Leemans and R.H. Brakenhoff, A genetic explanation of Slaughter's concept of field cancerization: evidence and clinical implications, Cancer Res. 63 (2003), 1727-1230.

[45] E. Giovannucci and S. Ogino, DNA methylation, field effects, and colorectal cancer, J Natl Cancer Inst 97 (2005), 13171319.

[46] D.P. Slaughter, H.W. Southwick and W. Smejkal, Field cancerization in oral stratified squamous epithelium; clinical implications of multicentric origin, Cancer 6 (1953), 963-968.

[47] D. Schottenfeld, Epidemiology of lung cancer, in: Lung cancer: principles and practice, H.I. Pass, J.B. Mitchell, D.H Johnson and A.T. Turrisi, eds, Lippincott-Raven Publishers: Philadelphia, 1996, pp. 305-321.

[48] M.F. Fraga, E. Ballestar, M.F. Paz, S. Ropero, F. Setien, M.L. Ballestar, D. Heine-Suner, J.C. Cigudosa, M. Urioste, J. Benitez, M. Boix-Chornet, A. Sanchez-Aguilera, C. Ling, E. Carlsson, P. Poulsen, A. Vaag, Z. Stephan, T.D. Spector, Y.Z. Wu, C. Plass and M. Esteller, Epigenetic differences arise during the lifetime of monozygotic twins, Proc Natl Acad Sci USA 102 (2005), 10604-10609.

[49] L. Shen, Y. Kondo, G.L. Rosner, L. Xiao, N.S. Hernandez, J. Vilaythong, P.S. Houlihan, R.S. Krouse, A.R. Prasad, J.G. Einspahr, J. Buckmeier, D.S. Alberts, S.R. Hamilton and J.P. Issa, MGMT promoter methylation and field defect in sporadic colorectal cancer, J Natl Cancer Inst 97 (2005), 1330-1338.

[50] J.A. Tsou, L.Y.C. Shen, K.D. Siegmund, T.I. Long, P.W. Laird, C. Seneviratne, M.N. Koss, H.I. Pass, J.A. Hagen and I.A. Laird-Offringa, Distinct DNA methylation patterns in malignant mesothelioma, lung adenocarcinoma, and nontumor lung, Lung Cancer 47 (2005), 193-204.

[51] K.M. Kerr, Pulmonary preinvasive neoplasia, J. Clin. Pathol. 54 (2001), 257-271.

[52] Y. Shimosato, T. Kodama and T. Kameya, Morphogenesis of peripheral type adenocarcinoma of the lung., in Morphogenesis of lung cancer, Y. Shimosato, M.R. Melamed and P. Nettesheim, Editors. (1982), CRC Press: Boca Raton. 65-90.

[53] F.A. Carey, Pulmonary adenocarcinoma: classification and molecular biology, J. Pathol. 184 (1998), 229-230.

[54] W.H. Westra, Early glandular neoplasia of the lung, Respir. Res. 1 (2000), 163-169.

[55] W.H. Westra, R.J. Slebos, G.J. Offerhaus, S.N. Goodman, S.G. Evers, T.W. Kensler, F.B. Askin, S. Rodenhuis and R.H. Hruban, K-ras oncogene activation in lung adenocarcinomas from former smokers. Evidence that K-ras mutations are an early and irreversible event in the development of adenocarcinoma of the lung, Cancer 72 (1993), 432-438.

[56] W.H. Westra, I.O. Baas, R.H. Hruban, F.B. Askin, K. Wilson, G.J. Offerhaus and R.J. Slebos, K-ras oncogene activation in atypical alveolar hyperplasias of the human lung, Cancer Res. 56 (1996), 2224-2228.

[57] S. Niho, T. Yokose, K. Suzuki, T. Kodama, Y. Nishiwaki and K. Mukai, Monoclonality of atypical adenomatous hyperplasia of the lung, Am. J. Pathol. 154 (1999), 249-254.

[58] A. Berns, Stem cells for lung cancer? Cell 121 (2005), 811813.

[59] C.F. Kim, E.L. Jackson, A.E. Woolfenden, S. Lawrence, I. Babar, S. Vogel, D. Crowley, R.T. Bronson and T. Jacks, Identification of bronchioalveolar stem cells in normal lung and lung cancer, Cell 121 (2005), 823-835.

[60] W.D. Travis, T.V. Colby and B. Corrin, Histological Typing of Lung Cancer and Pleural Tumors, WHO International Histological Classification of Tumors, (3rd edition), Springer: Berlin, 1999, 29-

[61] W.D. Travis, K. Garg, W.A. Franklin, Wistuba, II, B. Sabloff, M. Noguchi, R. Kakinuma, M. Zakowski, M. Ginsberg, R. Padera, F. Jacobson, B.E. Johnson, F. Hirsch, E. Brambilla, D.B. Flieder, K.R. Geisinger, F. Thunnisen, K. Kerr, D. Yankelevitz, T.J. Franks, J.R. Galvin, D.W. Henderson, A.G. Nicholson, P.S. Hasleton, V. Roggli, M.S. Tsao, F. Cappuzzo and M. Vazquez, Evolving concepts in the pathology and computed tomography imaging of lung adenocarcinoma and bronchioloalveolar carcinoma, J Clin Oncol 23 (2005), 3279-3287.

[62] K. Nakanishi, T. Kawai, F. Kumaki, S. Hirot, M. Mukai and E. Ikeda, Expression of human telomerase RNA component and telomerase reverse transcriptase mRNA in atypical adenomatous hyperplasia of the lung, Hum. Pathol. 33 (2002), 697-702.

[63] C.F. Mountain, Revisions in the international system for staging lung cancer, Chest 111 (1997), 1710-1717.

[64] C.F. Mountain and C.M. Dresler, Regional lymph node classification for lung cancer staging, Chest 111 (1997), 17181723.

[65] H.T. Bjornsson, H. Cui, D. Gius, M.D. Fallin and A.P. Feinberg, The new field of epigenomics: implications for cancer and other common disease research, Cold Spring Harb Symp Quant Biol 69 (2004), 447-456.

[66] P. Wolf, Y.C. Hu, K. Doffek, D. Sidransky and S.A. Ahrendt, O6-Methylguanine-DNA methyltransferase promoter hypermethylation shifts the p53 mutational spectrum in non-small cell lung cancer, Cancer Res. 61 (2001), 8113-8117.

[67] H.S. Hsu, C.K. Wen, Y.A. Tang, R.K. Lin, W.Y. Li, W.H. Hsu and Y.C. ang, Promoter hypermethylation is the predominant mechanism in hMLH1 and hMSH2 deregulation and is a poor prognostic factor in nonsmoking lung cancer, Clin Cancer Res. 11 (2005), 5410-5416.

[68] M.F. Paz, S. Avila, M.F. Fraga, M. Pollan, G. Capella, M.A. Peinado, M. Sanchez-Cespedes, J.G. Herman and M. Esteller, Germ-line variants in methyl-group metabolism genes and susceptibility to DNA methylation in normal tissues and human primary tumors, Cancer Res. 62 (2002), 4519-4524.

[69] H. Shen, L. Wang, M.R. Spitz, W.K. Hong, L. Mao and Q. Wei, A novel polymorphism in human cytosine DNAmethyltransferase-3B promoter is associated with an increased risk of lung cancer, Cancer Res. 62 (2002), 49924995 . 
[70] S.J. Lee, H.S. Jeon, J.S. Jang, S.H. Park, G.Y. Lee, B.H. Lee, C.H. Kim, Y.M. Kang, W.K. Lee, S. Kam, R.W. Park, I.S. Kim, Y.L. Cho, T.H. Jung and J.Y. Park, DNMT3B polymorphisms and risk of primary lung cancer, Carcinogenesis $\mathbf{2 6}$ (2005), 403-409.

[71] T.S. Lin, H. Lee, R.A. Chen, M.L. Ho, C.Y. Lin, Y.H. Chen, Y.Y. Tsai, M.C. Chou and Y.W. Cheng, An association of DNMT3b protein expression with P16INK4a promoter hypermethylation in non-smoking female lung cancer with human papillomavirus infection, Cancer Lett 226 (2005), 77 84.

[72] F.D. Gilliland, H.J. Harms, R.E. Crowell, Y.F. Li, R. Willink and S.A. Belinsky, Glutathione S-transferase P1 and NADPH quinone oxidoreductase polymorphisms are associated with aberrant promoter methylation of P16(INK4a) and $\mathrm{O}(6)$-methylguanine-DNA methyltransferase in sputum, Cancer Res. 62 (2002), 2248-2252.

[73] B. Vogelstein and K.W. Kinzler, Cancer genes and the pathways they control, Nat Med 10 (2004), 789-799.

[74] W.A. Franklin, A.F. Gazdar, J. Haney, Wistuba, II, F.G. La Rosa, T. Kennedy, D.M. Ritchey and Y.E. Miller, Widely dispersed p53 mutation in respiratory epithelium. A novel mechanism for field carcinogenesis, J Clin Invest 100 (1997), 2133-2137.

[75] Wistuba, II, C. Behrens, A.K. Virmani, G. Mele, S. Milchgrub, L. Girard, J.W. Fondon, 3rd, H.R. Garner, B. McKay, F. Latif, M.I. Lerman, S. Lam, A.F. Gazdar and J.D. Minna, High resolution chromosome $3 p$ allelotyping of human lung cancer and preneoplastic/preinvasive bronchial epithelium reveals multiple, discontinuous sites of $3 p$ allele loss and three regions of frequent breakpoints, Cancer Res. 60 (2000), 1949-1960.

[76] E.R. Zabarovsky, M.I. Lerman and J.D. Minna, Tumor suppressor genes on chromosome $3 p$ involved in the pathogenesis of lung and other cancers, Oncogene 21 (2002), 69156935.

[77] I.W. Park, Wistuba, II, A. Maitra, S. Milchgrub, A.K. Virmani, J.D. Minna and A.F. Gazdar, Multiple clonal abnormalities in the bronchial epithelium of patients with lung cancer, J Natl Cancer Inst 91 (1999), 1863-1868.

[78] U. Grepmeier, W. Dietmaier, J. Merk, P.J. Wild, E.C. Obermann, M. Pfeifer, F. Hofstaedter, A. Hartmann and M. Woenckhaus, Deletions at chromosome $2 q$ and $12 p$ are early and frequent molecular alterations in bronchial epithelium and NSCLC of long-term smokers, Int J Oncol 27 (2005), 481-488.

[79] M. Sanchez-Cespedes, S.A. Ahrendt, S. Piantadosi, R. Rosell, M. Monzo, L. Wu, W.H. Westra, S.C. Yang, J. Jen and D. Sidransky, Chromosomal alterations in lung adenocarcinoma from smokers and nonsmokers, Cancer Res. 61 (2001), 1309-1313.

[80] Wistuba, II, L. Mao and A.F. Gazdar, Smoking molecular damage in bronchial epithelium, Oncogene 21 (2002), 7298 7306.

[81] T.M. Holm, L. Jackson-Grusby, T. Brambrink, Y. Yamada, W.M. Rideout, 3rd and R. Jaenisch, Global loss of imprinting leads to widespread tumorigenesis in adult mice, Cancer Cell 8 (2005), 275-285.

[82] R. Kaplan, K. Luettich, A. Heguy, N.R. Hackett, B.G. Harvey and R.G. Crystal, Monoallelic up-regulation of the imprinted H19 gene in airway epithelium of phenotypically normal cigarette smokers, Cancer Res. 63 (2003), 1475-1482.

[83] M. Kondo, H. Suzuki, R. Ueda, H. Osada, K. Takagi, T. Takahashi and T. Takahashi, Frequent loss of imprinting of the $\mathrm{H} 19$ gene is often associated with its overexpression in human lung cancers, Oncogene 10 (1995), 1193-1198.

[84] M. Kohda, H. Hoshiya, M. Katoh, I. Tanaka, R. Masuda, T. Takemura, M. Fujiwara and M. Oshimura, Frequent loss of imprinting of IGF2 and MEST in lung adenocarcinoma, $\mathrm{Mol}$ Carcinog 31 (2001), 184-191.

[85] J.P. Issa, P.M. Vertino, C.D. Boehm, I.F. Newsham and S.B. Baylin, Switch from monoallelic to biallelic human IGF2 promoter methylation during aging and carcinogenesis, Proc Natl Acad Sci USA 93 (1996), 11757-11762.

[86] C.J. Piyathilake, A.R. Frost, W.C. Bell, D. Oelschlager, H. Weiss, G.L. Johanning, A. Niveleau, D.C. Heimburger and W.E. Grizzle, Altered global methylation of DNA: en epigenetic difference in susceptibility for lung cancer is associated with its progression, Hum. Path. 32 (2001), 856-862.

[87] B.N. Trinh, T.I. Long, A.E. Nickel, D. Shibata and P.W. Laird, DNA methyltransferase deficiency modifies cancer susceptibility in mice lacking DNA mismatch repair, $\mathrm{Mol}$ Cell Biol 22 (2002), 2906-2917.

[88] F. Gaudet, J.G. Hodgson, A. Eden, L. Jackson-Grusby, J. Dausman, J.W. Gray, H. Leonhardt and R. Jaenisch, Induction of tumors in mice by genomic hypomethylation, Science 300 (2003), 489-492.

[89] S.A. Belinsky, W.A. Palmisano, F.D. Gilliland, L.A. Crooks, K.K. Divine, S.A. Winters, M.J. Grimes, H.J. Harms, C.S. Tellez, T.M. Smith, P.P. Moots, J.F. Lechner, C.A. Stidley and R.E. Crowell, Aberrant promoter methylation in bronchial epithelium and sputum from current and former smokers, Cancer Res. 62 (2002), 2370-2377.

[90] K. Fujiwara, N. Fujimoto, M. Tabata, K. Nishii, K. Matsuo, K. Hotta, T. Kozuki, M. Aoe, K. Kiura, H. Ueoka and M. Tanimoto, Identification of epigenetic aberrant promoter methylation in serum DNA is useful for early detection of lung cancer, Clin Cancer Res. 11 (2005), 1219-1225.

[91] S.A. Belinsky, K.J. Nikula, W.A. Palmisano, R. Michels, G. Saccomanno, E. BGabrielson, S.B. Baylin and J.G. Herman, Aberrant methylation of p16 INK4a is an early event in lung cancer and potential biomarker for early diagnosis, Proc. Natl. Acad. Sci. USA 95 (1998), 11891-11896.

[92] M. Kersting, C. Friedl, A. Kraus, M. Behn, W. Pankow and M. Schuermann, Differential frequencies of p16INK4a promoter hypermethylation, p53 mutation, and K-ras mutation in exfoliative material mark the development of lung cancer in symptomatic chronic smokers, J. Clin. Oncol. 18 (2000), 3221-3229.

[93] W.A. Palmisano, K.K. Divine, G. Saccomanno, F.D. Gilliland, S.B. Baylin, J.G. Herman and S.A. Belinsky, Predicting lung cancer by detecting aberrant promoter methylation in sputum, Cancer Res. 60 (2000), 5954-5958.

[94] S.A. Belinsky, K.C. Liechty, F.D. Gentry, H.J. Wolf, J. Rogers, K. Vu, J. Haney, T.C. Kennedy, F.R. Hirsch, Y. Miller, W.A. Franklin, J.G. Herman, S.B. Baylin, P.A. Bunn and T. Byers, Promoter hypermethylation of multiple genes in sputum precedes lung cancer incidence in a high-risk cohort, Cancer Res. 66 (2006), 3338-3344.

[95] D.H. Kim, J.S. Kim, Y.I. Ji, Y.M. Shim, H. Kim, J. Han and J. Park, Hypermethylation of RASSF1 A promoter is associated with the age at starting smoking and a poor prognosis in primary non-small cell lung cancer, Cancer Res. 63 (2003), 3743-3746.

[96] C.J. Marsit, D.H. Kim, M. Liu, P.W. Hinds, J.K. Wiencke, H.H. Nelson and K.T. Kelsey, Hypermethylation of RASSF1A and BLU tumor suppressor genes in non-small 
cell lung cancer: implications for tobacco smoking during adolescence, Int J Cancer 114 (2005), 219-223.

[97] J. Roche and H.A. Drabkin, The role of semaphorins in lung cancer, Clin Lung Cancer 3 (2001), 145-150.

[98] T. Kuroki, F. Trapasso, S. Yendamuri, A. Matsuyama, H Alder, N.N. Williams, L.R. Kaiser and C.M. Croce, Allelic loss on chromosome $3 \mathrm{p} 21.3$ and promoter hypermethylation of semaphorin 3B in non-small cell lung cancer, Cancer Res. 63 (2003), 3352-3355.

[99] S.A. Belinsky, D.M. Klinge, C.A. Stidley, J.P. Issa, J.G. Herman, T.H. March and S.B. Baylin, Inhibition of DNA methylation and histone deacetylation prevents murine lung cancer, Cancer Res. 63 (2003), 7089-7093.

[100] S.A. Belinsky, S.S. Snow, K.J. Nikula, G.L. Finch, C.S Tellez and W.A. Palmisano, Aberrant $\mathrm{CpG}$ island methylation of the p16(INK4a) and estrogen receptor genes in rat lung tumors induced by particulate carcinogens, Carcinogenesis 23 (2002), 335-339.

[101] V. Dasari, M. Gallup, H. Lemjabbar, I. Maltseva and N. McNamara, Epithelial-mesenchymal Transition in Lung Cancer: Is Tobacco the "Smoking Gun"? Am J Respir Cell Mol Biol (2006).

[102] J. Mazieres, B. He, L. You, Z. Xu and D.M. Jablons, Wnt signaling in lung cancer, Cancer Lett 222 (2005), 1-10.

[103] J. Behrens and B. Lustig, The Wnt connection to tumorigenesis, Int J Dev Biol 48 (2004), 477-487.

[104] N. Ahuja and J.P. Issa, Aging, methylation and cancer, Histol Histopathol 15 (2000), 835-842.

[105] T. Waki, G. Tamura, M. Sato and T. Motoyama, Age-related methylation of tumor suppressor and tumor-related genes: an analysis of autopsy samples, Oncogene 22 (2003), 41284133.

[106] A.J. Simpson, O.L. Caballero, A. Jungbluth, Y.T. Chen and L.J. Old, Cancer/testis antigens, gametogenesis and cancer, Nat Rev Cancer 5 (2005), 615-625.

[107] K. Tajima, Y. Obata, H. Tamaki, M. Yoshida, Y.T. Chen, M.J. Scanlan, L.J. Old, H. Kuwano, T. Takahashi, T. Takahashi and T. Mitsudomi, Expression of cancer/testis (CT) antigens in lung cancer, Lung Cancer 42 (2003), 23-33.

[108] S.J. Jang, J.-C. Soria, L. Wang, K.A. Hassan, R.C. Morice, G.L. Walsh, W.K. Hong and L. Mao, Activation of melanoma antigen tumor antigens occurs early in lung carcinogenesis, Cancer Res. 61 (2001), 7959-7963.

[109] K.A. Olaussen, J.C. Soria, Y.W. Park, H.J. Kim, S.H. Kim, J.Y. Ro, F. Andre and S.J. Jang, Assessing abnormal gene promoter methylation in paraffin-embedded sputum from patients with NSCLC, Eur J Cancer 41 (2005), 2112-2119.

[110] F. de Fraipont, D. Moro-Sibilot, S. Michelland, E. Brambilla, C. Brambilla and M.C. Favrot, Promoter methylation of genes in bronchial lavages: a marker for early diagnosis of primary and relapsing non-small cell lung cancer? Lung Cancer 50 (2005), 199-209.

[111] S. Modi, A. Kubo, H. Oie, A.B. Coxon, A. Rehmatulla and F.J. Kaye, Protein expression of the RB-related gene family and SV40 large T antigen in mesothelioma and lung cancer, Oncogene 19 (2000), 4632-4639.

[112] Y. Kurasono, T. Ito, Y. Kameda, N. Nakamura and H. Kitamura, Expression of cyclin D1, retinoblastoma gene protein, and p16 MTS1 protein in atypical adenomatous hyperplasia and adenocarcinoma of the lung. An immunohistochemical analysis, Virchows Arch 432 (1998), 207-215.

[113] K. Kashiwabara, T. Oyama, T. Sano, T. Fukuda and T. Nakajima, correlation between the methylation status of the p16/CDKN2A gene and the expression of the p16 and Rb proteins in primary non-small cell lung cancer, Int. J. Cancer 79 (1998), 215-220.

[114] H. Tanaka, Y. Fujii, H. Hirabayashi, S. Miyoshi, M. Sakaguchi, H.-E. Yoon and H. Matsuda, Disruption of the RB pathway and cell-proliferative activity in non-small cell lung cancers, Int. J. Cancer 79 (1998), 111-115.

[115] R. Tanaka, D. Wang, Y. Morishita, Y. Inadome, Y. Minami, T. Iijima, S. Fukai, T. Goya and M. Noguchi, Loss of function of p16 gene and prognosis of pulmonary adenocarcinoma, Cancer 103 (2005), 608-615.

[116] K. Nakanishi, T. Kawai, F. Kumaki, S. Hiroi, M. Mukai and E. Ikeda, Survivin expression in atypical adenomatous hyperplasia of the lung, Am. J. Pathol. 120 (2003), 712-719.

[117] H. Hayashi, T. Ito, T. Yazawa, M. Ikeda, Y. Inayama, Y. Nakatani, Y. Kameda, N. Nakamura and H. Kitamura, Reduced expression of p27/Kip1 is associated with the development of pulmonary adenocarcinoma, J. Pathol. 192 (2000), 26-31.

[118] M. Tominaga, N. Sueoka, K. Irie, K. Iwanaga, O. Tokunaga, S. Hayashi, K. Nakachi and E. Sueoka, Detection and discrimination of preneoplastic and early stages of lung adenocarcinoma using hnRNP B1 combined with the cell cyclerelated markers p16, cyclin D1, and Ki-67, Lung Cancer 40 (2003), 45-53.

[119] S. Kitaguchi, Y. Takeshima, T. Nishisaka and K. Inai, Proliferative activity, p53 expression and loss of heterozygosity on $3 \mathrm{p}, 9 \mathrm{p}$ and $17 \mathrm{p}$ in atypical adenomatous hyperplasia of the lung, Hiroshima J Med Sci 47 (1998), 17-25.

[120] M. Yamasaki, Y. Takeshima, S. Fujii, S. Kitaguchi, M. Matsuura, K. Tagawa and K. Inai, Correlation between genetic alterations and histopathological subtypes in bronchioloalveolar carcinoma and atypical adenomatous hyperplasia of the lung, Pathol Int 50 (2000), 778-785.

[121] K. Takamochi, T. Ogura, K. Suzuki, H. Kawasaki, Y. Kurashima, T. Yokose, A. Ochiai, K. Nagai, Y. Nishiwaki and $\mathrm{H}$. Esumi, Loss of heterozygosity on chromosomes $9 \mathrm{q}$ and $16 \mathrm{p}$ in atypical adenomatous hyperplasia concomitant with adenocarcinoma of the lung, Am J Pathol 159 (2001), 1941-1948.

[122] H. Kohno, K. Hiroshima, T. Toyozaki, T. Fujisawa and H. Ohwada, p53 mutation and allelic loss of chromosome 3p, 9p of preneoplastic lesions in patients with nonsmall cell lung carcinoma, Cancer 85 (1999), 341-347.

[123] A. Marchetti, S. Pellegrini, G. Bertacca, F. Buttitta, P. Gaeta, V. Carnicelli, V. Nardini, P. Griseri, A. Chella, C.A. Angeletti and G. Bevilacqua, FHIT and p53 gene abnormalities in bronchioloalveolar carcinomas. Correlations with clinicopathological data and K-ras mutations, J Pathol 184 (1998), 240-246.

[124] K.M. Kerr, S.J. MacKenzie, S. Ramasami, G.I. Murray, N. Fyfe, A.D. Chapman, M.C. Nicolson and G. King, Expression of Fhit, cell adhesion molecules and matrix metalloproteinases in atypical adenomatous hyperplasia and pulmonary adenocarcinoma., J. Pathol. 203 (2004), 638-644.

[125] M. van Slegtenhorst, R. de Hoogt, C. Hermans, M. Nellist, B. Janssen, S. Verhoef, D. Lindhout, A. van den Ouweland, D. Halley, J. Young, M. Burley, S. Jeremiah, K. Woodward, J. Nahmias, M. Fox, R. Ekong, J. Osborne, J. Wolfe, S. Povey, R.G. Snell, J.P. Cheadle, A.C. Jones, M. Tachataki, D. Ravine, J.R. Sampson, M.P. Reeve, P. Richardson, F. Wilmer, C. Munro, T.L. Hawkins, T. Sepp, J.B. Ali, S. Ward, A.J. Green, J.R. Yates, J. Kwiatkowska, E.P. Henske, M.P. Short, J.H. Haines, S. Jozwiak and D.J. Kwiatkowski, Identification 
of the tuberous sclerosis gene TSC1 on chromosome 9q34, Science 277 (1997), 805-808.

[126] T.E.C.T.S. Consortium, Identification and characterization of the tuberous sclerosis gene on chromosome 16. The European Chromosome 16 Tuberous Sclerosis Consortium, Cell 75 (1993), 1305-1315.

[127] K. Suzuki, T. Ogura, T. Yokose, K. Nagai, K. Mukai, T. Kodama, Y. Nishiwaki and H. Esumi, Loss of heterozygosity in the tuberous sclerosis gene associated regions in adenocarcinoma of the lung accompanied by multiple atypical adenomatous hyperplasia, Int J Cancer 79 (1998), 384-389.

[128] K. Takamochi, T. Ogura, T. Yokose, A. Ochiai, K. Nagai, Y. Nishiwaki, K. Suzuki and H. Esumi, Molecular analysis of the TSC1 gene in adenocarcinoma of the lung, Lung Cancer 46 (2004), 271-281.

[129] W.G. Jiang, J. Sampson, T.A. Martin, L. Lee-Jones, G. Watkins, A. Douglas-Jones, K. Mokbel and R.E. Mansel, Tuberin and hamartin are aberrantly expressed and linked to clinical outcome in human breast cancer: the role of promoter methylation of TSC genes, Eur J Cancer 41 (2005), $1628-1636$.

[130] M. Sanchez-Cespedes, P. Parrella, M. Esteller, S. Nomoto, B. Trink, J.M. Engles, W.H. Westra, J.G. Herman and D. Sidransky, Inactivation of LKB1/STK11 is a common event in adenocarcinomas of the lung, Cancer Res. 62 (2002), 3659-3662.

[131] H. Ghaffar, F. Sahin, M. Sanchez-Cepedes, G.H. Su, M. Zahurak, D. Sidransky and W.H. Westra, LKB1 protein expression in the evolution of glandular neoplasia of the lung, Clin Cancer Res. 9 (2003), 2998-3003.

[132] P. Fernandez, J. Carretero, P.P. Medina, A.I. Jimenez, S. Rodriguez-Perales, M.F. Paz, J.C. Cigudosa, M. Esteller, L. Lombardia, M. Morente, L. Sanchez-Verde, T. Sotelo and M. Sanchez-Cespedes, Distinctive gene expression of human lung adenocarcinomas carrying LKB1 mutations, Oncogene 23 (2004), 5084-5091.

[133] N. Seki, T. Takasu, K. Mandai, M. Nakata, H. Saeki, Y. Heike, I. Takata, Y. Segawa, T. Hanafusa and E. K., Expression of eukaryotic initiation factor $4 \mathrm{E}$ in atypical adenomatous hyperplasia and adenocarcinoma of the human peripheral lung, Clin. Cancer Res. 8 (2002), 3046-3053.

[134] C.A. Eads, K.D. Danenberg, K. Kawakami, L.B. Saltz, C. Blake, D. Shibata, P.V. Danenberg and P.W. Laird, MethyLight: a high-throughput assay to measure DNA methylation, Nucleic Acids Res. 28 (2000), E32.

[135] W.B. Coleman and A.G. Rivenbark, Quantitative DNA methylation analysis: the promise of high-throughput epigenomic diagnostic testing in human neoplastic disease, $J$ Mol Diagn 8 (2006), 152-156.

[136] S. Rodenhuis and R.J. Slebos, The ras oncogenes in human lung cancer, Am Rev Respir Dis 142 (1990), S27-S30.

[137] S. Rodenhuis and R.J. Slebos, Clinical significance of ras oncogene activation in human lung cancer, Cancer Res. 52 (1992), 2665s-2669s.

[138] H. Shigematsu and A.F. Gazdar, Somatic mutations of epidermal growth factor receptor signaling pathway in lung cancers, Int J Cancer 118 (2006), 257-262.

[139] C.A. Cooper, F.A. Carby, V.J. Bubb, D. Lamb, K.M. Kerr and A.H. Wyllie, The pattern of K-ras mutation in pulmonary adenocarcinoma defines a new pathway of tumour development in the human lung, J Pathol 181 (1997), 401-404.

[140] S. Toyooka, M. Tokumo, H. Shigematsu, K. Matsuo, H. Asano, K. Tomii, S. Ichihara, M. Suzuki, M. Aoe, H. Date, A.F. Gazdar and N. Shimizu, Mutational and epigenetic ev- idence for independent pathways for lung adenocarcinomas arising in smokers and never smokers, Cancer Res. 66 (2006), 1371-1375.

[141] Y. Yatabe, T. Kosaka, T. Takahashi and T. Mitsudomi, EGFR mutation is specific for terminal respiratory unit type adenocarcinoma, Am J Surg Pathol 29 (2005), 633-639.

[142] Y. Yoshida, T. Shibata, A. Kokubu, K. Tsuta, Y. Matsuno, Y. Kanai, H. Asamura, R. Tsuchiya and S. Hirohashi, Mutations of the epidermal growth factor receptor gene in atypical adenomatous hyperplasia and bronchioloalveolar carcinoma of the lung, Lung Cancer $\mathbf{5 0}$ (2005), 1-8.

[143] J.O. Lee, A.A. Russo and N.P. Pavletich, Structure of the retinoblastoma tumour-suppressor pocket domain bound to a peptide from HPV E7, Nature 391 (1998), 859-865.

[144] A. Destro, P. Bianchi, M. Alloisio, L. Laghi, S. Di Gioia, A. Malesci, U. Cariboni, G. Gribaudi, G. Bulfamante, A. Marchetti, S. Bosari, M. Infante, G. Ravasi and M. Roncalli, K-ras and p16(INK4A)alterations in sputum of NSCLC patients and in heavy asymptomatic chronic smokers, Lung Cancer 44 (2004), 23-32.

[145] K.K. Divine, L.C. Pulling, P.G. Marron-Terada, K.C. Liechty, T. Kang, A.G. Schwartz, T.J. Bocklage, T.A. Coons, F.D. Gilliland and S.A. Belinsky, Multiplicity of abnormal promoter methylation in lung adenocarcinomas from smokers and never smokers, Int J Cancer 114 (2005), 400-405.

[146] L.C. Pulling, K.K. Divine, D.M. Klinge, F.D. Gilliland, T. Kang, A.G. Schwartz, T.J. Bocklage and S.A. Belinsky, Promoter hypermethylation of the O6-methylguanine-DNA methyltransferase gene: more common in lung adenocarcinomas from never-smokers than smokers and associated with tumor progression, Cancer Res. 63 (2003), 4842-4848.

[147] A. Shimada, J. Kano, T. Ishiyama, C. Okubo, T. Iijima, Y. Morishita, Y. Minami, Y. Inadome, Y. Shu, S. Sugita, T. Takeuchi and M. Noguchi, Establishment of an immortalized cell line from a precancerous lesion of lung adenocarcinoma, and genes highly expressed in the early stages of lung adenocarcinoma development, Cancer Sci. 96 (2005), 668-675.

[148] Y. Shu, T. Iijima, W. Sun, J. Kano, T. Ishiyama, C. Okubo, Y. Anami, R. Tanaka, S. Fukai and M. Noguchi, The ACIN1 gene is hypermethylated in early stage lung adenocarcinoma, J. Thor. Oncol. 1 (2006), 160-167.

[149] T.V. Colby, Wistuba, II and A. Gazdar, Precursors to pulmonary neoplasia, Adv Anat Pathol 5 (1998), 205-215.

[150] H. Awaya, Y. Takeshima, V.J. Amatya, H. Ishida, M. Yamasaki, N. Kohno and K. Inai, Loss of expression of Ecadherin and beta-catenin is associated with progression of pulmonary adenocarcinoma, Pathol Int 55 (2005), 14-18.

[151] N. Kanomata, R. Nakahara, T. Oda, Y. Aoyagi, G. Ishii, T. Yokose, T. Hasebe, K. Nagai, H. Yokozaki and A. Ochiai, Expression and localization of mRNAs for matrix metalloproteinases and their inhibitors in mixed bronchioloalveolar carcinomas with invasive components, Mod Pathol 18 (2005), 828-837.

[152] K. Nakanishi, T. Kawai, F. Kumaki, S. Hiroi, M. Mukai, E. Ikeda, C.E. Koering and E. Gilson, Expression of mRNAs for telomeric repeat binding factor (TRF)-1 and TRF2 in atypical adenomatous hyperplasia and adenocarcinoma of the lung, Clin. Cancer Res. 9 (2003), 1105-1111.

[153] T. Yoshikawal, Y. Aoyagi, K. Kodama, T. Kamijo, H. Yonou, T. Yokose, G. Ishii, T. Oda, K. Takamochi, K. Nagai, Y. Nishiwaki, N. Shimizu and A. Ochiai, Topographical distribution of allelic loss in individual lung adenocarcinomas with lymph node metastases, Mod Pathol 17 (2004), 204-213. 
[154] Y. Aoyagi, T. Yokose, Y. Minami, A. Ochiai, T. Iijima, Y. Morishita, T. Oda, K. Fukao and M. Noguchi, Accumulation of losses of heterozygosity and multistep carcinogenesis in pulmonary adenocarcinoma, Cancer Res. 61 (2001), 79507954.

[155] H. Awaya, Y. Takeshima, V.J. Amatya, O. Furonaka, K. Tagawa, N. Kohno and K. Inai, Inactivation of the p16 gene by hypermethylation and loss of heterozygosity in adenocarcinoma of the lung, Pathol Int 54 (2004), 486-489.

[156] K.M. Kerr, F.A. Carey, G. King and D. Lamb, Atypical alveolar hyperplasia: relationship with pulmonary adenocarcinoma, p53, and c-erbB-2 expression, J Pathol 174 (1994), 249-256.

[157] H. Shigematsu, T. Takahashi, M. Nomura, K. Majmudar, M. Suzuki, H. Lee, Wistuba, II, K.M. Fong, S. Toyooka, N. Shimizu, T. Fujisawa, J.D. Minna and A.F. Gazdar, Somatic mutations of the HER2 kinase domain in lung adenocarcinomas, Cancer Res. 65 (2005), 1642-1646.

[158] O. Furonaka, Y. Takeshima, H. Awaya, K. Kushitani, N. Kohno and K. Inai, Aberrant methylation and loss of expression of O-methylguanine-DNA methyltransferase in pulmonary squamous cell carcinoma and adenocarcinoma, Pathol Int 55 (2005), 303-309.

[159] M.J. Fazzari and J.M. Greally, Epigenomics: beyond CpG islands, Nat Rev Genet 5 (2004), 446-455.

[160] R.M. Brena, T.H. Huang and C. Plass, Quantitative assessment of DNA methylation: potential applications for disease diagnosis, classification, and prognosis in clinical settings, $J$ Mol Med 84 (2006), 365-377.

[161] L.A. Shevde and D.R. Welch, Metastasis suppressor pathways - an evolving paradigm, Cancer Lett. 198 (2003), 1-20.

[162] J.C. Berger, D. Vander Griend, W.M. Stadler and C. RinkerSchaeffer, Metastasis suppressor genes: signal transduction, cross-talk, and the potential for modulating the behavior of metastatic cells, Anti-Cancer Drugs 15 (2004), 559-568.

[163] A.M. Marchevsky, J.-H. Qiao, S. Krajisnik, J.M. Mirocha and R.J. McKenna, The prognostic significance of intranodal isolated tumor cells and micrometastases in patients with non-small cell carcinoma of the lung, J. Thorac. Cardiovasc. Surg. 126 (2003), 551-557.

[164] P. Kogerman, M.S. Sy and L.A. Culp, Counter-selection for over-expressed human CD44s in primary tumors versus lung metastases in a mouse fibrosarcoma model, Oncogene $\mathbf{1 5}$ (1997), 1407-1416.

[165] J.S. Nam, Y. Ino, Y. Kanai, M. Sakamoto and S. Hirohashi, 5-aza-2'-deoxycytidine restores the E-cadherin system in Ecadherin-silenced cancer cells and reduces cancer metastasis, Clin Exp Metastasis 21 (2004), 49-56.

[166] J.R. Graff, E. Gabrielson, H. Fujii, S.B. Baylin and J.G. Herman, Methylation patterns of the E-cadherin 5' CpG island are unstable and reflect the dynamic, heterogeneous loss of E-cadherin expression during metastatic progression, $J$ Biol Chem 275 (2000), 2727-2732.

[167] P. Gonzalez-Gomez, M.J. Bello, M.E. Alonso, C. Aminoso, I. Lopez-Marin, J.M. De Campos, A. Isla, M. Gutierrez and J.A. Rey, Promoter methylation status of multiple genes in brain metastases of solid tumors, Int J Mol Med 13 (2004), 93-98.

[168] T. Kashima, K. Nakamura, J. Kawaguchi, M. Takanashi, T. Ishida, H. Aburatani, A. Kudo, M. Fukayama and A.E. Grigoriadis, Overexpression of cadherins suppresses pulmonary metastasis of osteosarcoma in vivo, Int J Cancer 104 (2003), $147-154$.
[169] S. Gamou, Y. Shimasato, G.T. Merlino and N. Shimizu, Methylation status of epidermal growth factor receptor gene in lung carcinoma cells, Jpn. J. Cancer Res. 79 (1988), 989995.

[170] E.J. Ormerod, C.A. Everett and I.R. Hart, Enhanced experimental metastatic capacity of a human tumor line following treatment with 5-azacytidine, Cancer Res. 46 (1986), 884890.

[171] L. Olsson and J. Forchhammer, Induction of the metastatic phenotype in a mouse tumor model by 5-azacytidine, and characterization of an antigen associated with metastatic activity, Proc Natl Acad Sci USA 81 (1984), 3389-3393.

[172] H. Liu, W. Liu, Y. Wu, Y. Zhou, R. Xue, C. Luo, L. Wang, W. Zhao, J.D. Jiang and J. Liu, Loss of epigenetic control of synuclein-gamma gene as a molecular indicator of metastasis in a wide range of human cancers, Cancer Res. 65 (2005), 7635-7643.

[173] N.J. Belshaw, G.O. Elliott, E.A. Williams, D.M. Bradburn, S.J. Mills, J.C. Mathers and I.T. Johnson, Use of DNA from human stools to detect aberrant $\mathrm{CpG}$ island methylation of genes implicated in colorectal cancer, Cancer Epidemiol Biomarkers Prev 13 (2004), 1495-1501.

[174] D.R. Yates, I. Rehman, M. Meuth, S.S. Cross, F.C. Hamdy and J.W. Catto, Methylational urinalysis: a prospective study of bladder cancer patients and age stratified benign controls, Oncogene 25 (2006), 1984-1988.

[175] A. Olek, J. Oswald and J. Walter, A modified and improved method for bisulphite based cytosine methylation analysis, Nucleic Acids Res. 24 (1996), 5064-5066.

[176] J.K. Gohagan, P.M. Marcus, R.M. Fagerstrom, P.F. Pinsky, B.S. Kramer, P.C. Prorok, S. Ascher, W. Bailey, B. Brewer, T. Church, D. Engelhard, M. Ford, M. Fouad, M. Freedman, E. Gelmann, D. Gierada, W. Hocking, S. Inampudi, B. Irons, C.C. Johnson, A. Jones, G. Kucera, P. Kvale, K. Lappe, W. Manor, A. Moore, H. Nath, S. Neff, M. Oken, M. Plunkett, H. Price, D. Reding, T. Riley, M. Schwartz, D. Spizarny, R. Yoffie and C. Zylak, Final results of the Lung Screening Study, a randomized feasibility study of spiral CT versus chest X-ray screening for lung cancer, Lung Cancer 47 (2005), 9-15.

[177] K. Travis, Lung Cancer Screening for All? Not yet, panel says, J. Natl. Cancer Inst. 96 (2004), 900-901.

[178] J.A. Crestanello, M.S. Allen, J.R. Jett, S.D. Cassivi, F.C.r. Nichols, S.J. Swensen, C. Deschamps and P.C. Pairolero, Thoracic surgical operations in patients enrolled in a computed tomographic screening trial, J. Thorac. Cardiovasc. Surg. 128 (2004), 254-259.

[179] S.J. Swensen, T.E. Hartman, D.E. Midthun, J.A. Sloan, A.M. Sykes, G.L. Aughenbaugh GL and M.A Clemens, Lung cancer screening with CT: Mayo Clinic experience, Radiology 226 (2003), 756-761.

[180] Y. Ohde, K. Nagai, J. Yoshida, M. Nishimura, K. Takahashi, K. Suzuki, K. Takamochi, T. Yokose and Y. Nishiwaki, The proportion of consolidation to ground-glass opacity on high resolution $\mathrm{CT}$ is a good predictor for distinguishing the population of non-invasive peripheral adenocarcinoma, Lung Cancer 42 (2003), 303-310.

[181] S.A. Ahrendt, J.T. Chow, L.H. Xu, S.C. Yang, C.F. Eisenberger, M. Esteller, J.G. Herman, L. Wu, P.A. Decker, J. Jen and D. Sidransky, Molecular detection of tumor cells in bronchoalveolar lavage fluid from patients with early stage lung cancer, J. Natl. Cancer Inst. 91 (1999), 333-339.

[182] M. Esteller, M. Sanchez-Cespedes, R. Rosell, D. Sidransky, S.B. Baylin and J.G. Herman, Detection of aberrant promoter 
hypermethylation of tumor suppressor genes in serum DNA from non-small cell lung cancer patients, Cancer Res. 59 (1999), 67-70.

[183] S.A. Leon, B. Shapiro, D.M. Sklaroff and M.J. Yaros, Free DNA in the serum of cancer patients and the effect of therapy, Cancer Res. 37 (1977), 646-650.

[184] H. Usadel, J. Brabender, K.D. Danenberg, C. Jeronimo, S. Harden, J. Engles, P.V. Danenberg, S. Yang and D. Sidransky, Quantitative adenomatous polyposis coli promoter methylation analysis in tumor tissue, serum, and plasma DNA of patients with lung cancer, Cancer Res. 62 (2002), 371-375.

[185] M. Pellise, A. Castells, A. Gines, R. Agrelo, M. Sole, S. Castellvi-Bel, G. Fernandez-Esparrach, J. Llach, M. Esteller, J.M. Bordas and J.M. Pique, Detection of lymph node micrometastases by gene promoter hypermethylation in samples obtained by endosonography-guided fine needle aspiration biopsy, Clin. Cancer Res. 10 (2004), 4444-4449.

[186] C. Konaka, N. Ikeda, T. Hiyoshi, K. Tsuji, T. Hirano, N. Kawate, Y. Ebihara and H. Kato, Peripheral non-small cell lung cancers $2.0 \mathrm{~cm}$ or less in diameter: proposed criteria for limited pulmonary resection based upon clinicopathological presentation, Lung Cancer 21 (1998), 185-191.

[187] T. Koike, M. Terashima, T. Takizawa, T. Watanabe, Y. Kurita and A. Yokoyama, Clinical analysis of small-sized peripheral lung cancer, J Thorac Cardiovasc Surg 115 (1998), 10151020 .

[188] T. Takizawa, M. Terashima, T. Koike, T. Watanabe, Y. Kurita, A. Yokoyama and K. Honma, Lymph node metastasis in small peripheral adenocarcinoma of the lung, $J$ Thorac Cardiovasc Surg 116 (1998), 276-280.

[189] H. Matsuguma, R. Nakahara, M. Anraku, T. Kondo, Y. Tsuura, Y. Kamiyama, K. Mori and K. Yokoi, Objective definition and measurement method of ground-glass opacity for planning limited resection in patients with clinical stage IA adenocarcinoma of the lung, Eur J Cardiothorac Surg 25 (2004), 1102-1106.

[190] H. Asamura, H. Nakayama, H. Kondo, R. Tsuchiya, Y. Shimosato and T. Naruke, Lymph node involvement, recurrence, and prognosis in resected small, peripheral, non-small-cell lung carcinomas: are these carcinomas candidates for videoassisted lobectomy? J Thorac Cardiovasc Surg 111 (1996), 1125-1134.

[191] J.R. Dunn, D. Panutsopulos, M.W. Shaw, J. Heighway, R. Dormer, E.N. Salmo, S.G. Watson, J.K. Field and T. Liloglou, METH-2 silencing and promoter hypermethylation in NSCLC, Br J Cancer 91 (2004), 1149-1154.

[192] J. Brabender, H. Usadel, K.D. Danenberg, R. Metzger, P.M. Schneider, R.V. Lord, K. Wickramasinghe, C.E. Lum, J. Park, D. Salonga, J. Singer, D. Sidransky, A.H. Holscher, S.J. Meltzer and P.V. Danenberg, Adenomatous polyposis coli gene promoter hypermethylation in non-small cell lung cancer is associated with survival, Oncogene 20 (2001), 35283532.

[193] N. Yanagawa, G. Tamura, H. Oizumi, N. Takahashi, Y. Shimazaki and T. Motoyama, Promoter hypermethylation of tumor suppressor and tumor-related genes in non-small cell lung cancers, Cancer Sci. 94 (2003), 589-592.

[194] A.K. Virmani, A. Rathi, U.G. Sathyanarayana, A. Padar, C.X. Huang, H.T. Cunningham, A.J. Farinas, S. Milchgrub, D.M. Euhus, M. Gilcrease, J.G. Herman, J.D. Minna and A.F. Gazdar, Aberrant methylation of the Adenomatous Polyposis Coli (APC) gene promoter $1 \mathrm{~A}$ in breast and lung carcinomas, Clin. Cancer Res. 7 (2001), 1998-2004.
[195] O. Topaloglu, M.O. Hoque, Y. Tokumaru, J. Lee, E. Ratovitski, D. Sidransky and C.S. Moon, Detection of promoter hypermethylation of multiple genes in the tumor and bronchoalveolar lavage of patients with lung cancer, Clin. Cancer Res. 10 (2004), 2284-2288.

[196] A. Virmani, A. Rathi, S. Heda, K. Sugio, C. Lewis, V. Tonk, T. Takahashi, J.A. Roth, J.D. Minna, D.M. Euhus and A.F. Gazdar, Aberrant methylation of the cyclin D2 promoter in primary small cell, nonsmall cell lung and breast cancers, Int J Cancer 107 (2003), 341-345.

[197] S. Nakata, K. Sugio, H. Uramoto, T. Oyama, T. Hanagiri, M. Morita and K. Yasumoto, The methylation status and protein expression of CDH1, p16(INK4A), and fragile histidine triad in nonsmall cell lung carcinoma: epigenetic silencing, clinical features, and prognostic significance, Cancer 106 (2006), 2190-2199.

[198] S. Zochbauer-Muller, K.M. Fong, A.K. Virmani, J. Geradts, A.F. Gazdar and J.D. Minna, Aberrant promoter methylation of multiple genes in non-small cell lung cancers, Cancer Res. 61 (2001), 249-255

199] J.S. Kim, J. Han, Y.M. Shim, J. Park and D.H. Kim, Aberrant methylation of $\mathrm{H}$-cadherin (CDH13) promoter is associated with tumor progression in primary nonsmall cell lung carcinoma, Cancer 104 (2005), 1825-1833.

[200] H. Kim, Y.M. Kwon, J.S. Kim, H. Lee, J.H. Park, Y.M. Shim, J. Han, P. J. and D.H. Kim, Tumor-specific methylation in bronchial lavage for the early detection of non-small-cell lung cancer, J. Clin. Oncol. 22 (2004), 2363-2370.

[201] T. Kobatake, M. Yano, S. Toyooka, K. Tsukuda, H. Dote, T. Kikuchi, M. Toyota, M. Ouchida, M. Aoe, H. Date, H.I. Pass, H. Doihara and N. Shimizu, Aberrant methylation of p57KIP2 gene in lung and breast cancers and malignant mesotheliomas, Oncol Rep 12 (2004), 1087-1092.

[202] S. Toyooka, M. Suzuki, R. Maruyama, K.O. Toyooka, K. Tsukuda, Y. Fukuyama, T. Lizasa, M. Aoe, H. Date, T. Fujisawa, N. Shimizu and A.F. Gazdar, The relationship between aberrant methylation and survival in non-small cell lung cancers, Br. J. Cancer Res. 91 (2004), 771-774.

[203] T. Hanabata, K. Tsukuda, S. Toyooka, M. Yano, M. Aoe, I. Nagahiro, Y. Sano, H. Date and N. Shimizu, DNA methylation of multiple genes and clinicopathological relationship of non-small cell lung cancers, Oncol Rep 12 (2004), 177-180.

[204] R. Cirincione, C. Lintas, D. Conte, L. Mariani, L. Roz, A.M. Vignola, U. Pastorino and G. Sozzi, Methylation profile in tumor and sputum samples of lung cancer patients detected by spiral computed tomography: a nested case-control study, Int J Cancer 118 (2006), 1248-1253.

[205] A. Lamy, R. Sesboue, J. Bourguignon, B. Dautreaux, J. Metayer, T. Frebourg and L. Thiberville, Aberrant methylation of the CDKN2a/p16INK4a gene promoter region in preinvasive bronchial lesions: a prospective study in highrisk patients without invasive cancer, Int J Cancer 100 (2002), 189-193.

[206] M. Seike, A. Gemma, Y. Hosoya, S. Hemmi, Y. Taniguchi, S. Fukuda, N. Yamanaka and S. Kudoh, Increase in the frequency of p16INK4 gene inactivation by hypermethylation in lung cancer during the process of metastasis and its relation to the status of p53, Clin. Cancer Res. 6 (2000), 4307-4313.

[207] P.G. Corn, M.K. Summers, F. Fogt, A.K. Virmani, A.F. Gazdar, T.D. Halazonetis and W.S. El-Deiry, Frequent hypermethylation of the 5' $\mathrm{CpG}$ island of the mitotic stress checkpoint gene $\mathrm{Chfr}$ in colorectal and non-small cell lung cancer, Carcinogenesis 24 (2003), 47-51. 
[208] M. Yano, S. Toyooka, K. Tsukuda, H. Dote, M. Ouchida, T. Hanabata, M. Aoe, H. Date, A.F. Gazdar and N. Shimizu, Aberrant promoter methylation of human DAB2 interactive protein (hDAB2IP) gene in lung cancers, Int J Cancer $\mathbf{1 1 3}$ (2005), 59-66.

[209] S. Toyooka, K.O. Toyooka, K. Miyajima, J.L. Reddy, M. Toyota, U.G. Sathyanarayana, A. Padar, M.S. Tockman, S. Lam, N. Shivapurkar and A.F. Gazdar, Epigenetic downregulation of death-associated protein kinase in lung cancers, Clin Cancer Res. 9 (2003), 3034-3041.

[210] L.C. Pulling, B.R. Vuillemenot, J.A. Hutt, T.R. Devereux and S.A. Belinsky, Aberrant promoter hypermethylation of the death-associated protein kinase gene is early and frequent in murine lung tumors induced by cigarette smoke and tobacco carcinogens, Cancer Res. 64 (2004), 3844-3848.

[211] D.-H. Kim, H.H. Nelson, J.K. Wiencke, D.C. Christiani, J.C. Wain, E.J. Mark and K.T. Kelsey, Promoter methylation of DAP-kinase: association with advanced stage in non-small cell lung cancer, Oncogene 20 (2001), 1765-1770.

[212] X. Tang, F.R. Khuri, J.J. Lee, B.L. Kemp, D. Liu, W.K. Hong and L. Mao, Hypermethylation of the death-associated protein (DAP) kinase promoter and aggressiveness in stage I non-small cell lung cancer., J. Natl. Cancer Inst. 92 (2000), $1511-1516$.

[213] S. Kikuchi, D. Yamada, T. Fukami, M. Masuda, M. SakuraiYageta, Y.N. Williams, T. Maruyama, H. Asamura, Y. Matsuno, M. Onizuka and Y. Murakami, Promoter methylation of DAL-1/4.1B predicts poor prognosis in non-small cell lung cancer, Clin Cancer Res. 11 (2005), 2954-2961.

[214] J.C. Lai, Y.W. Cheng, H.L. Chiou, M.F. Wu, C.Y.Chen and H. Lee, Gender difference in estrogen receptor alpha promoter hypermethylation and its prognostic value in non-small cell lung cancer, Int J Cancer 117 (2005), 974-980.

[215] J.P. Issa, S.B. Baylin and S.A. Belinsky, Methylation of the estrogen receptor $\mathrm{CpG}$ island in lung tumors is related to the specific type of carcinogen exposure, Cancer Res. 56 (1996), 3655-3658.

[216] H. Chen, M. Suzuki, Y. Nakamura, M. Ohira, S. Ando, T. Iida, T. Nakajima, A. Nakagawara and H. Kimura, Aberrant methylation of FBN2 in human non-small cell lung cancer, Lung Cancer 50 (2005), 43-49.

[217] D. Iliopoulos, G. Guler, S.Y. Han, D. Johnston, T. Druck, K.A. McCorkell, J. Palazzo, P.A. McCue, R. Baffa and K. Huebner, Fragile genes as biomarkers: epigenetic control of WWOX and FHIT in lung, breast and bladder cancer, Oncogene 24 (2005), 1625-1633.

[218] S. Zochbauer-Muller, K.M. Fong, A. Maitra, S. Lam, J. Geradts, R. Ashfaq, A.K. Virmani, S. Milchgrub, A.F. Gazdar and J.D. Minna, 5' CpG island methylation of the FHIT gene is correlated with loss of gene expression in lung and breast cancer, Cancer Res. 61 (2001), 3581-3585.

[219] R. Maruyama, K. Sugio, I. Yoshino, Y. Maehara and A.F. Gazdar, Hypermethylation of FHIT as a prognostic marker in nonsmall cell lung carcinoma, Cancer 100 (2004), 14721477.

[220] Y. Tomizawa, H. Iijima, T. Nomoto, Y. Iwasaki, Y. Otani, S. Tsuchiya, R. Saito, K. Dobashi, T. Nakajima and M. Mori, Clinicopathological significance of aberrant methylation of RARbeta2 at 3p24, RASSF1A at 3p21.3, and FHIT at 3p14.2 in patients with non-small cell lung cancer, Lung Cancer $\mathbf{4 6}$ (2004), 305-312.

[221] J.S. Kim, H. Kim, Y.M. Shim, J. Han, J. Park and D.H. Kim, Aberrant methylation of the FHIT gene in chronic smok- ers with early stage squamous cell carcinoma of the lung, Carcinogenesis 25 (2004), 2165-2171.

[222] M. Guo, Y. Akiyama, M.G. House, C.M. Hooker, E. Heath, E. Gabrielson, S.C. Yang, Y. Han, S.B. Baylin, J.G. Herman and M.V. Brock, Hypermethylation of the GATA genes in lung cancer, Clin Cancer Res. 10 (2004), 7917-7924.

[223] J.T. Chen, Y.W. Cheng, M.C. Chou, T. Sen-Lin, W.W. Lai, W.L. Ho and H. Lee, The correlation between aberrant connexin 43 mRNA expression induced by promoter methylation and nodal micrometastasis in non-small cell lung cancer, Clin Cancer Res. 9 (2003), 4200-4204.

[224] K. Eguchi, Y. Kanai, K. Kobayashi and S. Hirohashi, DNA hypermethylation at the D175S locus in non-small cell lung cancers: its association with smoking history, Cancer Res. 57 (1997), 4913-4915.

[225] D. Takai, Y. Yagi, K. Wakazono, N. Ohishi, Y. Morita, T. Sugimura and T. Ushijima, Silencing of HTR1B and reduced expression of EDN1 in human lung cancers, revealed by methylation-sensitive representational difference analysis, Oncogene 20 (2001), 7505-7513.

[226] M. Shiraishi, A. Sekiguchi, A.J. Oates, M.J. Terry and Y. Miyamoto, HOX gene clusters are hotspots of de novo methylation in CpG islands of human lung adenocarcinomas, Oncogene 21 (2002), 3659-3662.

[227] G. Heller, K.M. Fong, L. Girard, S. Seidl, A. EndPfutzenreuter, G. Lang, A.F. Gazdar, J.D. Minna, C.C. Zielinski and S. Zochbauer-Muller, Expression and methylation pattern of TSLC1 cascade genes in lung carcinomas, Oncogene 25 (2006), 959-968.

[228] U.G. Sathyanarayana, S. Toyooka, A. Padar, T. Takahashi, E. Brambilla, J.D. Minna and A.F. Gazdar, Epigenetic inactivation of laminin-5-encoding genes in lung cancers, Clin. Cancer Res. 9 (2003), 2665-2672.

[229] M. Nishioka, T. Kohno, M. Tani, N. Yanaihara, Y. Tomizawa, A. Otsuka, S. Sasaki, K. Kobayashi, T. Niki, A. Maeshima, Y. Sekido, J.D. Minna, S. Sone and J. Yokota, MYO18B, a candidate tumor suppressor gene at chromosome 22q12.1, deleted, mutated, and methylated in human lung cancer, Proc Natl Acad Sci U S A 99 (2002), 12269-12274.

[230] W.A. Palmisano, K.P. Crume, M.J. Grimes, S.A. Winters, M. Toyota, M. Esteller, N. Joste, S.B. Baylin and S.A. Belinsky, Aberrant promoter methylation of the transcription factor genes PAX5 alpha and beta in human cancers, Cancer Res. 63 (2003), 4620-4625.

[231] S. Zochbauer-Muller, K.M. Fong, J. Geradts, X. Xu, S. Seidl, A. End-Pfutzenreuter, G. Lang, G. Heller, C.C. Zielinski, A.F. Gazdar and J.D. Minna, Expression of the candidate tumor suppressor gene hSRBC is frequently lost in primary lung cancers with and without DNA methylation, Oncogene 24 (2005), 6249-6255.

[232] J.C. Soria, H.Y. Lee, J.I. Lee, L. Wang, J.P. Issa, B.L. Kemp, D.D. Liu, J.M. Kurie, L. Mao and F.R. Khuri, Lack of PTEN expression in non-small cell lung cancer could be related to promoter methylation, Clin Cancer Res. 8 (2002), 11781184.

[233] C.J. Marsit, S. Zheng, K. Aldape, P.W. Hinds, H.H. Nelson, J.K. Wiencke and K.T. Kelsey, PTEN expression in nonsmall-cell lung cancer: evaluating its relation to tumor characteristics, allelic loss, and epigenetic alteration, Hum Pathol 36 (2005), 768-776.

[234] A. Virmani, A. Rathi, K. Sugio, U.G. Sathyanarayana, S. Toyooka, F.C. Kischel, V. Tonk, A. Padar, T. Takahashi, J.A. Roth, D.M. Euhus, J.D. Minna and A.F. Gazdar, Aberrant 
methylation of TMS1 in small cell, non small cell lung cancer and breast cancer, Int J Cancer 106 (2003), 198-204.

[235] A.K. Virmani, A. Rathi, S. Zochbauer-Muller, N. Sacchi, Y. Fukuyama, D. Bryant, A. Maitra, S. Heda, K.M. Fong, F. Thunnissen, J.D. Minna and A.F. Gazdar, Promoter methylation and silencing of the retinoic acid receptor-beta gene in lung carcinomas, J. Natl. Cancer Inst. 92 (2000), 1303-1307.

[236] B.R. Vuillemenot, L.C. Pulling, W.A. Palmisano, J.A. Hutt and S.A. Belinsky, Carcinogen exposure differentially modulates RAR-beta promoter hypermethylation, an early and frequent event in mouse lung carcinogenesis, Carcinogenesis 25 (2004), 623-629.

[237] A. Lamy, J. Metayer, L. Thiberville, T. Frebourg and R. Sesboue, Re: Promoter methylation and silencing of the retinoic acid receptor-beta gene in lung carcinomas, $J$ Natl Cancer Inst 93 (2001), 66-68.

[238] M. Ito, G. Ito, M. Kondo, M. Uchiyama, T. Fukui, S. Mori, H. Yoshioka, Y. Ueda, K. Shimokata and Y. Sekido, Frequent inactivation of RASSF1A, BLU, and SEMA3B on 3p21.3 by promoter hypermethylation and allele loss in non-small cell lung cancer, Cancer Lett 225 (2005), 131-139.

[239] N. Choi, D.S. Son, I. Song, H.S. Lee, Y.S. Lim, M.S. Song, D.S. Lim, J. Lee, H. Kim and J. Kim, RASSF1A is not appropriate as an early detection marker or a prognostic marker for non-small cell lung cancer, Int J Cancer 115 (2005), 575-581.

[240] D.G. Burbee, E. Forgacs, S. Zochbauer-Muller, L. Shivakumar, K. Fong, B. Gao, D. Randle, M. Kondo, A.K. Virmani, S. Bader, Y. Sekido, F. Latif, S. Milchgrub, S. Toyooka, A.F. Gazdar, M.I. Lerman, E. Zabarovsky, M. White and J.D. Minna, Epigenetic inactivation of RASFF1A in lung and breast cancers and malignant phenotype suppression, J. Natl. Cancer Inst. 93 (2001), 691-699.

[241] R. Dammann, G. Yang and G.P. Pfeifer, Hypermethylation of the $\mathrm{CpG}$ island of Ras associated domain family 1A (RASSF1A), a putative tumor suppressor gene from the 3p21.3 locus, occurs in a large percentage of human breast cancers, Cancer Res. 61 (2001), 3105-3109.

[242] S. Honorio, A. Agathanggelou, M. Schuermann, W. Pankow, P. Viacava, E.R. Maher and F. Latif, Detection of RASSF1A aberrant promoter hypermethylation in sputum from chronic smokers and ductal carcinoma in situ from breast cancer patients., Oncogene 22 (2003), 147-150.

[243] M. Suzuki, H. Shigematsu, T. Takahashi, N. Shivapurkar, U.G. Sathyanarayana, T. Iizasa, T. Fujisawa and A.F. Gazdar, Aberrant methylation of Reprimo in lung cancer, Lung Cancer 47 (2005), 309-314.

[244] K. Sato, Y. Tomizawa, H. Iijima, R. Saito, T. Ishizuka, T. Nakajima and M. Mori, Epigenetic inactivation of the RUNX3 gene in lung cancer, Oncol Rep 15 (2006), 129-135.

[245] I. Krop, A. Player, A. Tablante, M. Taylor-Parker, J. LahtiDomenici, J. Fukuoka, S.K. Batra, N. Papadopoulos, W.G. Richards, D.J. Sugarbaker, R.L. Wright, J. Shim, T.A. Stamey, W.R. Sellers, M. Loda, M. Meyerson, R. Hruban, J. Jen and K. Polyak, Frequent HIN-1 Promoter Methylation and Lack of Expression in Multiple Human Tumor Types, Mol. Cancer Res. 2 (2004), 489-494.

[246] B. He, L. You, K. Uematsu, K. Zang, Z. Xu, A.Y. Lee, J.C. Costello, F. McCormick and D.M. Jablons, SOCS-3 is frequently silenced by hypermethylation and suppresses cell growth in human lung cancer, Proc. Natl. Acad. Sci. USA 100 (2003), 14133-14138.

[247] M. Suzuki, C. Hao, T. Takahashi, H. Shigematsu, N. Shivapurkar, U.G. Sathyanarayana, T. Iizasa, T. Fujisawa, K. Hiroshima and A.F. Gazdar, Aberrant methylation of SPARC in human lung cancers, Br J Cancer 92 (2005), 942-948.

[248] H.T. Zhang, X.F. Chen, M.H. Wang, J.C. Wang, Q.Y. Qi, R.M. Zhang, W.Q. Xu, Q.Y. Fei, F. Wang, Q.Q. Cheng, F. Chen, C.S. Zhu, S.H. Tao and Z. Luo, Defective expression of transforming growth factor beta receptor type II is associated with $\mathrm{CpG}$ methylated promoter in primary non-small cell lung cancer, Clin Cancer Res. 10 (2004), 2359-2367.

[249] N. Shivapurkar, S. Toyooka, K.O. Toyooka, J. Reddy, K. Miyajima, M. Suzuki, H. Shigematsu, T. Takahashi, G. Parikh, H.I. Pass, P.M. Chaudhary and A.F. Gazdar, Aberrant methylation of trail decoy receptor genes is frequent in multiple tumor types, Int. J. Cancer 109 (2004), 786-792.

[250] J. Mazieres, B. He, L. You, Z. Xu, A.Y. Lee, I. Mikami, N. Reguart, R. Rosell, F. McCormick and D.M. Jablons, Wnt inhibitory factor-1 is silenced by promoter hypermethylation in human lung cancer, Cancer Res. 64 (2004), 4717-4720. 


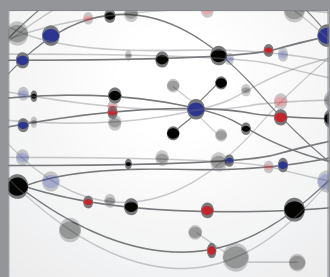

The Scientific World Journal
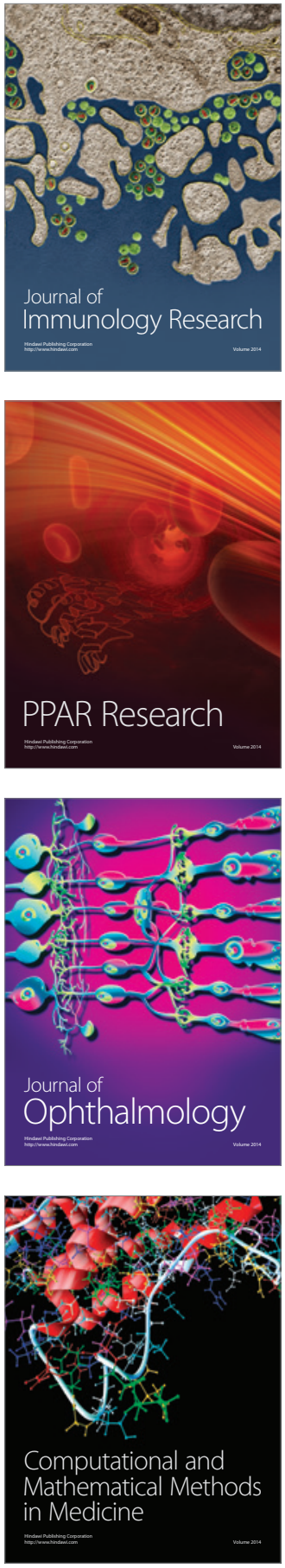

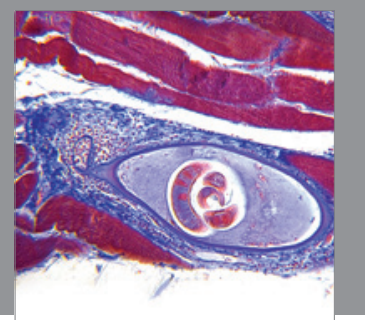

Gastroenterology

Research and Practice
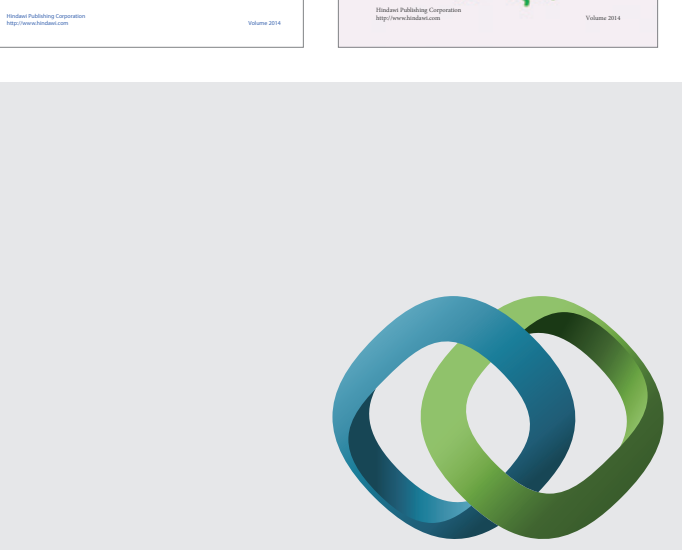

\section{Hindawi}

Submit your manuscripts at

http://www.hindawi.com
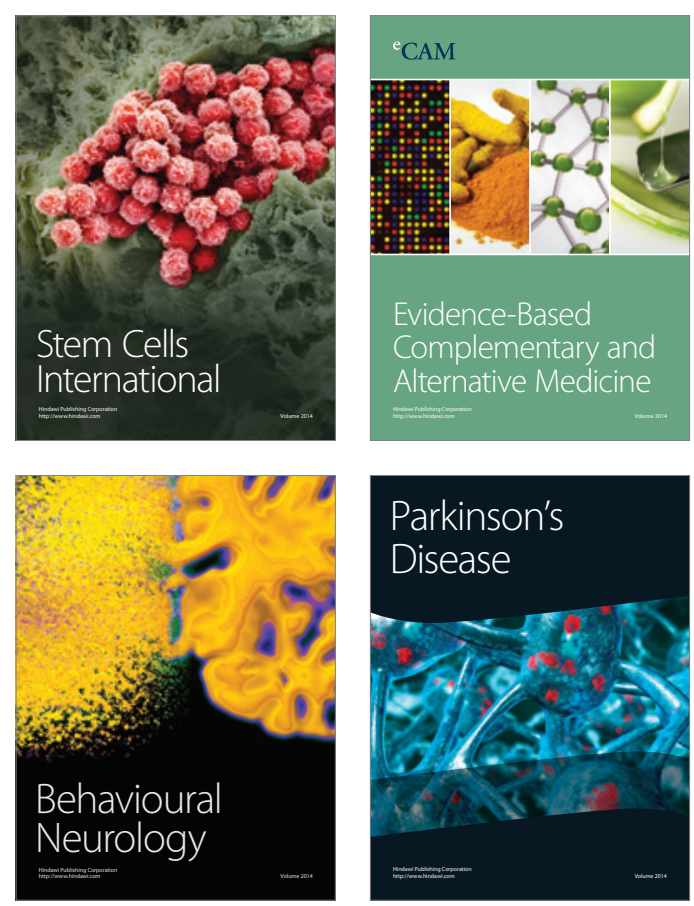

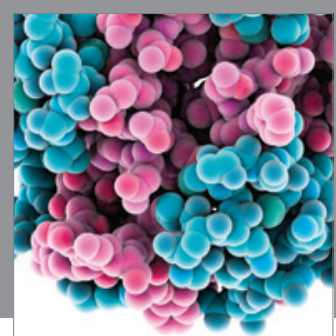

Journal of
Diabetes Research

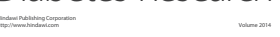

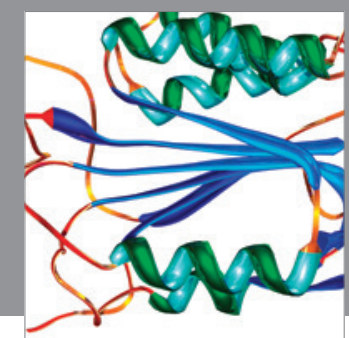

Disease Markers
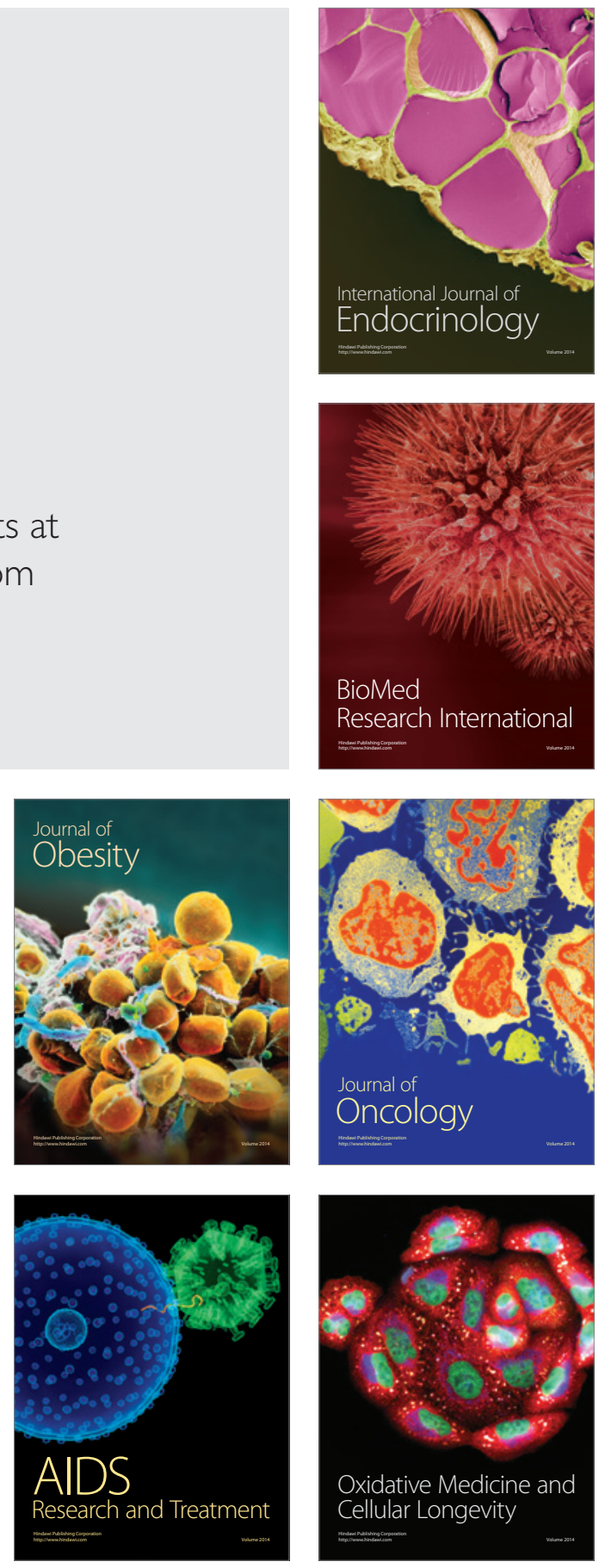